Article

\title{
Forest Fire Susceptibility and Risk Mapping Using Social/Infrastructural Vulnerability and Environmental Variables
}

\author{
Omid Ghorbanzadeh ${ }^{1, *(\mathbb{D}}$, Thomas Blaschke ${ }^{1}\left(\mathbb{D}\right.$, Khalil Gholamnia $^{2}$ and Jagannath Aryal ${ }^{3}(\mathbb{D})$ \\ 1 Department of Geoinformatics_Z_GIS, University of Salzburg, 5020 Salzburg, Austria \\ 2 Department of Remote Sensing and GIS, University of Tabriz, Tabriz 5166616471, Iran \\ 3 Discipline of Geography and Spatial Sciences, University of Tasmania, Hobart, TAS 7005, Australia \\ * Correspondence: omid.ghorbanzadeh@stud.sbg.ac.at
}

Received: 1 May 2019; Accepted: 30 August 2019; Published: 3 September 2019

\begin{abstract}
Forests fires in northern Iran have always been common, but the number of forest fires has been growing over the last decade. It is believed, but not proven, that this growth can be attributed to the increasing temperatures and droughts. In general, the vulnerability to forest fire depends on infrastructural and social factors whereby the latter determine where and to what extent people and their properties are affected. In this paper, a forest fire susceptibility index and a social/infrastructural vulnerability index were developed using a machine learning (ML) method and a geographic information system multi-criteria decision making (GIS-MCDM), respectively. First, a forest fire inventory database was created from an extensive field survey and the moderate resolution imaging spectroradiometer (MODIS) thermal anomalies product for 2012 to 2017. A forest fire susceptibility map was generated using 16 environmental variables and a k-fold cross-validation $(\mathrm{CV})$ approach. The infrastructural vulnerability index was derived with emphasis on different types of construction and land use, such as residential, industrial, and recreation areas. This dataset also incorporated social vulnerability indicators, e.g., population, age, gender, and family information. Then, GIS-MCDM was used to assess risk areas considering the forest fire susceptibility and the social/infrastructural vulnerability maps. As a result, most high fire susceptibility areas exhibit minor social/infrastructural vulnerability. The resulting forest fire risk map reveals that 729.61 ha, which is almost $1.14 \%$ of the study areas, is categorized in the high forest fire risk class. The methodology is transferable to other regions by localisation of the input data and the social indicators and contributes to forest fire mitigation and prevention planning.
\end{abstract}

Keywords: forest fire; social vulnerability; artificial neural network (ANN); k-fold cross-validation (CV); multi-criteria decision making (MCDA)

\section{Introduction}

Forest fires are a natural hazard that significantly affects Iran's forest areas due to their widespread environmental, economic, and social impacts. Forest fires are also considered as the leading force damaging forest resources, and they happen periodically in different severities [1]. Additionally, forest fires have increased due to an increase in the global temperature, the population, and human activities in forest areas [2]. In our study area, upward trends in both the number of forest fire events and burned areas are confirmed from 2012 until 2017. Forest fires cause some permanent alterations to forest areas, such as a reduction of plant communities and biodiversity, which can accelerate the deforestation processes [3]. However, there are also some advantages of forest fires, e.g., the elimination of harmful microorganisms, fungi, insects, and herbal disease, and soil enrichment by the nutrients and 
minerals released from the remaining ash [4]. However, there is no doubt that forest fires are a potential risk with economic and social consequences for the population who live in the forest areas [1]. A forest fire, like any natural hazard, demonstrates the potential threat from a natural process [5]. Northern Iran has approximately 1.2 million hectares and more than 300 hectares have burned annually. Most of these fires happen on the ground surface and affect young trees more often than old ones [6]. Thus, small trees and regeneration are largely affected and consequently, forest fire is considered as one of the main reasons of deforestation and desertification in northern Iran. Despite the high forest fire frequency in this area, there are no comprehensive susceptibility and risk analysis studies. Our study of the forest fire susceptibility in the northern forests of Iran is therefore timely and necessary. The use of the most recent spatial modelling approaches shall improve our knowledge on this problem and the results shall support fire management in this area.

The term risk is applied frequently for predicting uncertain future events of extreme consequences. Risk mapping focuses on low-probability, high-consequence adverse events that are stochastic in space. Risk assessment should be conducted when the predicted results are uncertain, but can be estimated [7]. Forest fire risk is assessed based on a scale of the probability that forest fires will occur and have destructive impacts on the population [8]. In other words, forest fire risk can be defined as the probability of devastating consequences, or likely losses (deaths, injuries, properties), caused by an interplay of forest fires and vulnerable communities in a given area [9]. Moreover, considering the indicators of social vulnerability to natural hazards is a relatively small part of both social and spatial research, especially in administrations worldwide [10]. In the present study, the forest fire risk mapping is used for identifying locations which bear the chance of loss, determined from estimates of forest fire susceptibility and social/infrastructural vulnerability.

The main aim of the present study is the forest fire risk mapping using environmental, social and infrastructure variables. For this goal, we required both socially vulnerable and susceptible areas to forest fires. Thus, a forest fire susceptibility map, or hazard map (in a more general expression), was generated considering sixteen relevant factors (i.e., topographic, meteorological, and human-made factors). In addition to the environmental variables, the human activity is also considered, as the conditioning factor plays a vital role in the forest fire susceptibility. Data from geographic information systems (GIS) and remote sensing (RS) is required for any natural hazard susceptibility mapping [11-15]. In addition to using relevant input data, an appropriate methodology is needed for useful hazard mapping. Vulnerability mapping concerning natural hazards is a multi-faceted procedure. Several aspects of vulnerability, including infrastructural and social indicators, should be considered in the final vulnerability map [16]. Generally, a clear understanding of the social issues of forest fire susceptibility, susceptibility and management are required to evaluate the damages to valued assets and resources and human life losses caused by forest fires $[17,18]$. Management of forest fire protection and estimating the responding costs is also paramount [19]. Although environmental variables (e.g., topography, temperature, vegetation) help assess the potential occurrence of forest fires, they are not sufficient for predicting where and to which extent forest fires can impact people or damage constructions [20,21]. Therefore, an ideal effort for forest fire prevention and risk mitigation must not only consider environmental variables, but also the different levels of social vulnerability of communities within residential areas in the study area. The social vulnerability can be determined from social systems and census data [22].

Demand for mapping the risky areas has grown as forest fires have increasingly affected populations and the environment. Universally, the growing frequency and damage from forest fires has resulted in many new studies. Based on the literature, there are two main methods and techniques for this aim, namely, data-based (machine learning (ML)) and knowledge-based methods that have been proposed and evaluated. Several studies used knowledge-based methods for forest fire susceptibility mappings, such as fuzzy logic $[23,24]$, the analytic hierarchy process (AHP) $[25,26]$ and the analytical network process [27]. However, ML methods such as logistic regression [5], artificial neural networks (ANN) [28-30], and Random Forest [31] are also conventional for mapping the susceptible areas of 
forest fires. Predicting the susceptible areas of any natural hazard has always been considered as an environmental management need [32]. Researchers attempt to turn this need into a systematic methodology based on well-established models and mathematical theories. They have also been increasingly developing/applying multivariate data analysis methods from both data mining and ML fields for predicting the susceptible areas of natural hazard based on previous distribution patterns and relevant factors [33]. In this study, we used the capabilities of an ANN method for predicting areas which potentially have a higher probability of forest fires. The forest fire inventory dataset includes the location of ignition and also the burned area. Therefore, the susceptibility map can represent a measure of the likelihood of ignition and the probability of spreading of forest fires based on the trained ANN method. At the same time, we generated both social and infrastructural vulnerability maps based on related vulnerabilities' indexes. Vulnerability is defined as the potential effect of a threat and considers the adaptive and endurance capacity of the affected units over time [7]. A wildfire vulnerability assessment of a forest area considers how populations can respond and adapt to the threat. Generally, the vulnerability of a place depends on various social indicators that have been considered by several studies, such as education level, age, unemployment rate, gender, accessibility to health centres, housing tenancy, and accessibility to government facilities [9,18,34-38]. These social indicators usually describe social inequities among people, which are presumed to increase a society's vulnerability to natural hazards [8]. Although in some areas in the world people living close to forest areas may be rich, in Iran, and most likely in the majority of cases, this population tends to be poorer. In the latter case, social vulnerability is relatively high since it is more difficult to recover from the impact of a hazard [39]. These people are also more sensitive to the threat of any natural hazards, such as forest fire occurrences, because socially vulnerable residents are generally less able to deal with threats from nature [18]. We used 22 social indicators and 11 infrastructural indicators for mapping both social and infrastructural vulnerabilities.

GIS-based multi-criteria decision analysis (GIS-MCDA) was used for both weighting and data aggregation. GIS-MCDA is a useful modelling methodology in the spatial sciences that can consider data with their spatial information [40]. Capabilities of GIS and MCDA have been well combined to solve a wide range of spatial problems [41]. The integration of MCDAs with the capabilities of GIS provides a smart spatial modelling methodology for identifying the relative significance of indicators [42]. AHP is one of the most commonly used methods in GIS-MCDA approaches [43]. This method supports the weighting process based on experts' judgments, which are organized in pairwise comparison matrices. The high knowledge of experts plays a crucial role in preparing useful pairwise comparison matrices [44].The resulting vulnerability maps indicate the elements-at-risk. However, the forest fire susceptibility mapping results in a map depicting hazardous areas [9]. A simple map overlay within the GIS environment was used to generate the risk map. Overlaying the social vulnerability map with the hazard map is a common approach for risk map generation that is used in several studies $[8,18,45,46]$. Our study considered both social vulnerabilities and the map of natural hazards susceptibility, resulting in a more comprehensive risk assessment of forest fire in the study area. Risk analysis provides scientists and managers with a better understanding about the location and potential effects of forest fires on the economy, society and the environment [7]. Risk mapping can transparently address the management of issues, which are existing in the forestry areas and the mitigation of adverse consequences of forest fires.

\section{Material and Methods}

The workflow of this study for the forest fire risk mapping is as follow:

- Preparing the conditioning forest fire factors.

- Defining and preparing the social/infrastructural vulnerability factors localised for the case study area.

- Preparing a forest fire inventory map from the hotspots of MODIS enhanced using field survey GPS polygons. 
- Applying the artificial neural network (ANN) method for the spatial prediction of forest fire susceptibility mapping.

- Applying the GIS-MCDA method for the social/infrastructural vulnerability mapping.

- Validating the performances of the ANN method using the receiver operating characteristics (ROC) curve and the root mean square error (RMSE).

The methodologies (see Figure 1) and the experimental results are organized in the following sections. Further descriptions and discussions regarding the resulting maps can be found in the discussions and conclusion section.

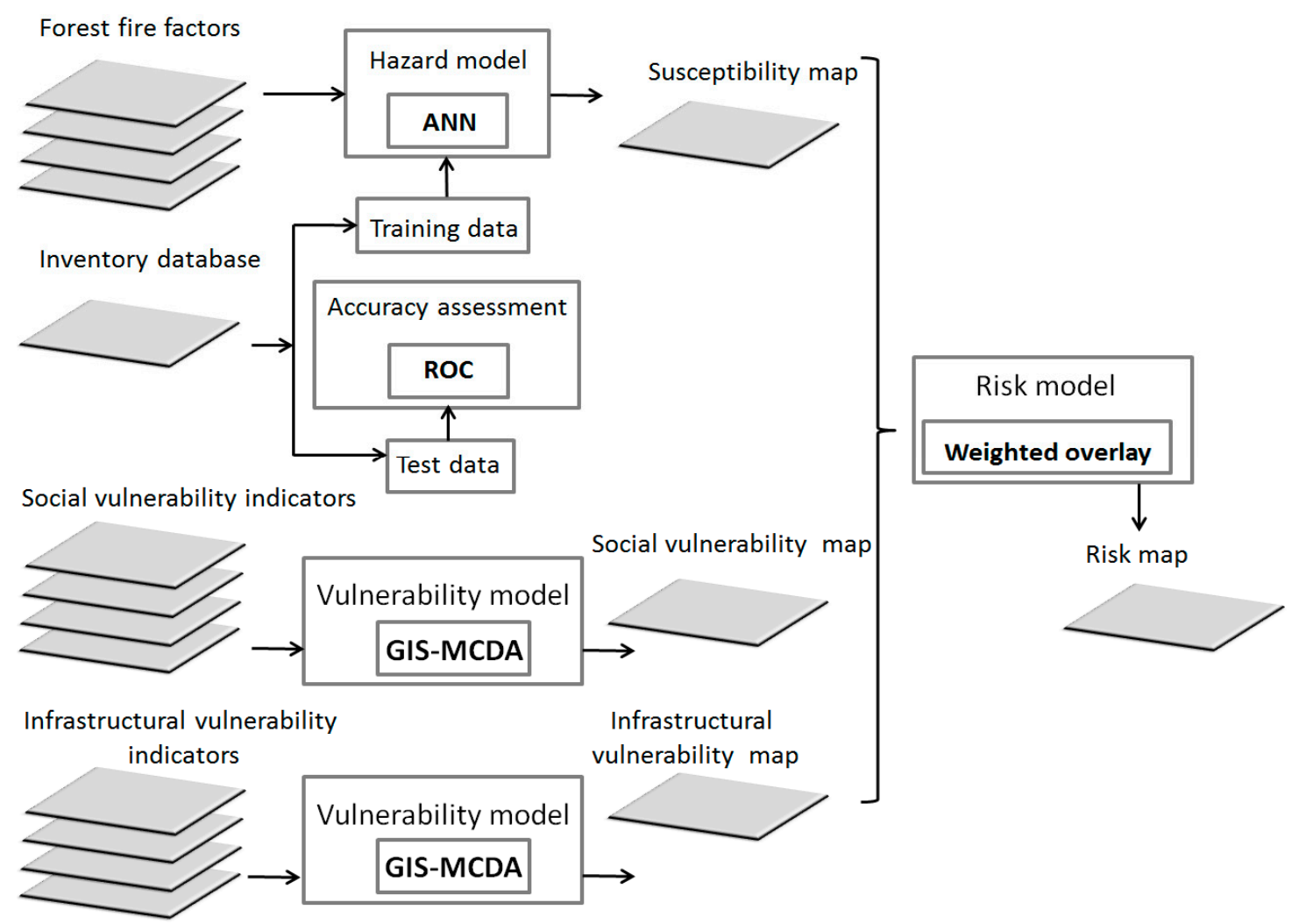

Figure 1. Methodology scheme and workflow.

\subsection{Study Area}

The case study was the forestry area of Amol County in the Mazandaran province of northern Iran (Figure 2). Our study area has an expanse of $646 \mathrm{~km}^{2}$ and is essential for its natural forests and as one of the common recreational centres of the country. The study area attracts tourists from all over the country. The altitude ranges from $100 \mathrm{~m}$ in valleys to approximately $2500 \mathrm{~m}$ above mean sea level in mountainous areas in the southern part. Other topographical and environmental characteristics are described in Table 1. The study area is potentially vulnerable to forest fires, which are considered as a common problem in the region. There are more than 20 villages in the study area, mostly in valleys and some located in remote forest areas. The most common activity among the population is animal husbandry. However, there are also orchards, including walnuts and apple gardens, and even some agricultural activities. 

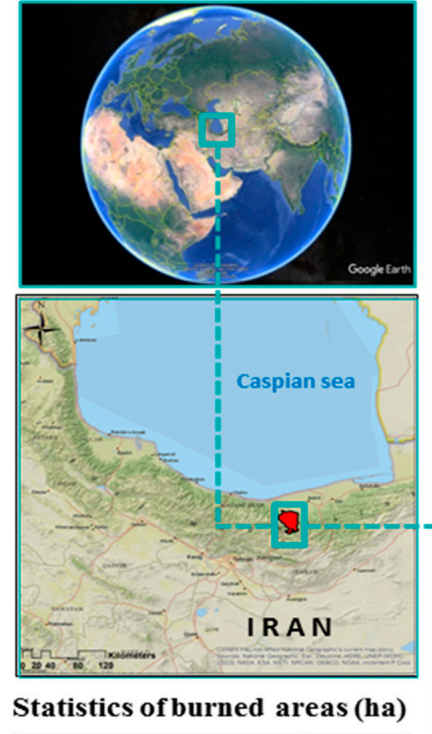

\begin{tabular}{|l|l|}
\hline Count: & 34 \\
\hline Minimum: & 0,41 \\
\hline Maximum: & 59,73 \\
\hline Sum: & 500 \\
\hline Mean: & 12,00 \\
\hline Standard Deviation: & 10,51 \\
\hline
\end{tabular}

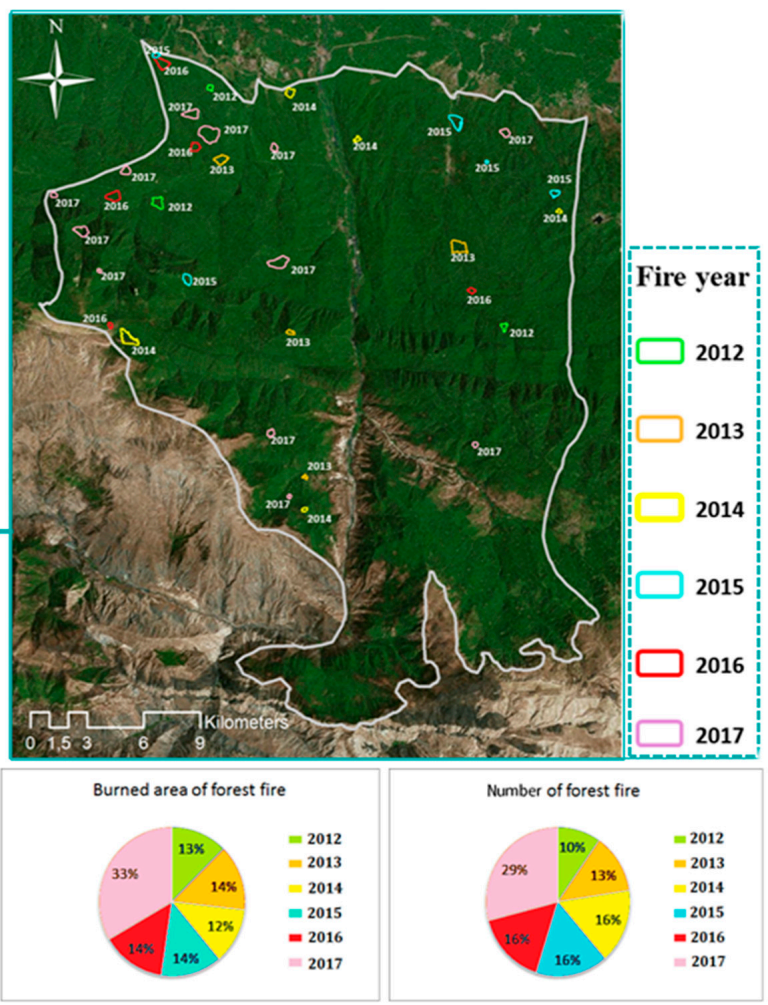

Figure 2. Study area with polygons indicating the approximate location of regions burned between 2012 and 2017.

\subsection{Data Used in the Analysis}

To generate the forest fire susceptibility map of our study area, 16 relevant factors including environmental variables were considered as forest fire occurrence data.

The relevant topographic factors are slope aspect, slope, altitude, plan curvature, landform, and the topographic wetness index (TWI). The meteorological factors are annual temperature, potential solar radiation, and wind effect. The considered vegetation factor was the normalized difference vegetation index (NDVI). The NDVI factor was created for the high vegetated summer period, applying Landsat-8 Operational Land Imagery (OLI) $30 \mathrm{~m}$ resolution, retrieved from the USGS archive (http: //earthexplorer.usgs.gov). The human-made factors are the distance to the nearest village, land use, and the distance to roads and recreational areas. The hydrological factors are annual rainfall and the distance to streams (see Table 1).

The topographic factors were derived from the Advanced Spaceborne Thermal Emission and Reflection Radiometer (ASTER) (NASA, California Institute of Technology, USA) Global Digital Elevation Model (GDEM) with an approximate resolution of $30 \mathrm{~m}$. Related topographic factors are considered as important forest fire factors that impact the fire's separate pattern in forests [47]. These factors have been widely used for forest fire susceptibility mapping [48]. The slope factor is essential because increasing in slope angle results in fire spreading more quickly [27]. Since usually north-facing slopes are colder and moister than those of south, the risk of forest fire on south-facing slopes is higher [49]. The presence of higher moister at higher altitude shows the importance of this factor [50]. The factor of wind effect was generated by three different factors, including the degree of wind direction, wind speed $(\mathrm{m} / \mathrm{s})$, and altitude layer [51]. The solar radiation varies from nearly $0.3 \mathrm{KWH} / \mathrm{m}^{2}$ to more than $1.8 \mathrm{KWH} / \mathrm{m}^{2}$ and this range is classified in five classes based on natural breaks. In terms of human-made factors, various distance measures were considered. The distances and intervals for the classified layers were defined based on their importance regarding forest fires, the radius of human activities, the literature, and expert experiences [24] (see Figure 3). 
Table 1. Forest fire relevant factors, classes by corresponding areas, and percent of the burned areas in each class.

\begin{tabular}{|c|c|c|c|c|c|c|c|}
\hline Factors & Class & $\begin{array}{c}\text { \# of Pixels in } \\
\text { Domain }\end{array}$ & Area (ha) & $\begin{array}{c}\% \text { of } \\
\text { Domain }\end{array}$ & $\begin{array}{l}\text { Area of Forest } \\
\text { Fires (ha) }\end{array}$ & $\begin{array}{l}\% \text { of Forest } \\
\text { Fires }\end{array}$ & Source \\
\hline \multirow[t]{9}{*}{ Slope aspect } & (1) Flat & 413 & 32.66 & 0.05 & 0.23 & 0.04 & \multirow{9}{*}{$\begin{array}{c}\text { ASTER } \\
\text { DEM }\end{array}$} \\
\hline & (2) North & 163,477 & $12,929.5$ & 20.017 & 78.87 & 15.74 & \\
\hline & (3) Northeast & 157,185 & $12,431.86$ & 16.25 & 74.90 & 14.95 & \\
\hline & (4) East & 111,057 & 8783.56 & 13.60 & 59.27 & 11.83 & \\
\hline & (5) Southeast & 64,513 & 5102.32 & 7.9 & 35.55 & 7.09 & \\
\hline & (6) South & 59,425 & 4699.96 & 7.27 & 53.12 & 10.6 & \\
\hline & (7) Southwest & 69,288 & 5480.03 & 8.48 & 65.06 & 12.98 & \\
\hline & (8) West & 89,748 & 7098 & 10.98 & 83.87 & 16.71 & \\
\hline & (9) Northwest & 101,549 & 8031.57 & 12.43 & 50.21 & 10.02 & \\
\hline \multicolumn{7}{|l|}{ Slope (\%) } & \multirow{7}{*}{$\begin{array}{c}\text { ASTER } \\
\text { DEM }\end{array}$} \\
\hline & (1) $0-5$ & 52,438 & 4147.35 & 6.42 & 49.13 & 9.8 & \\
\hline & (2) $5-10$ & 131,189 & $10,375.82$ & 16.06 & 129.72 & 25.89 & \\
\hline & (3) $10-15$ & 165,158 & $13,062.45$ & 20.22 & 160.07 & 31.95 & \\
\hline & (4) $15-20$ & 132,343 & $10,467.09$ & 16.20 & 68.49 & 13.67 & \\
\hline & (5) $20-30$ & 172,740 & $13,662.11$ & 21.15 & 55.58 & 11.09 & \\
\hline & (6) $30<$ & 162,787 & $12,874.92$ & 19.93 & 37.93 & 7.57 & \\
\hline \multicolumn{7}{|l|}{ Altitude (m) } & \multirow{7}{*}{$\begin{array}{c}\text { ASTER } \\
\text { DEM }\end{array}$} \\
\hline & (1) $500>$ & 267,103 & $20,609.83$ & 31.76 & 272.50 & 54.39 & \\
\hline & (2 500-1000 & 221,070 & $17,057.90$ & 26.28 & 139.98 & 27.93 & \\
\hline & (3) 1000-1500 & 175,496 & $13,541.38$ & 20.86 & 33.66 & 6.72 & \\
\hline & (4) 1500-2000 & 131,112 & $10,116.68$ & 15.59 & 51.22 & 10.23 & \\
\hline & (5) 2000-2500 & 44,074 & 3400.77 & 5.59 & 3.57 & 0.71 & \\
\hline & (6) $2500<$ & 2064 & 159.25 & 0.24 & 0 & & \\
\hline \multirow[t]{6}{*}{$\begin{array}{c}\text { Annual } \\
\text { temperature } \\
\left({ }^{\circ} \mathrm{C}\right)\end{array}$} & & & & & & & \multirow{6}{*}{ SMOAC } \\
\hline & (1) $10>$ & 30,663 & 2425.1 & 3.75 & 0 & 0 & \\
\hline & (2) $10-12$ & 190,487 & $15,065.7$ & 23.29 & 3.61 & 0.72 & \\
\hline & (3) $12-14$ & 213,835 & $16,912.3$ & 26.15 & 92.93 & 18.55 & \\
\hline & (4) $14-16$ & 234,441 & $18,542.0$ & 28.67 & 162.79 & 32.48 & \\
\hline & (5) $16<$ & 148,230 & $11,723.6$ & 18.1 & 241.12 & 48.25 & \\
\hline \multicolumn{7}{|l|}{$\begin{array}{l}\text { Annual rainfall } \\
(\mathrm{mm})\end{array}$} & \multirow{6}{*}{ SMOAC } \\
\hline & (1) $400-450$ & 40,288 & 3186.40 & 4.92725 & 0 & 0 & \\
\hline & (2) $450-500$ & 129,427 & $10,236.4$ & 15.8290 & 0 & 0 & \\
\hline & (3) $500-550$ & 138,521 & $10,955.7$ & 16.9412 & 30.56 & 6.10 & \\
\hline & (4) 550-600 & 311,886 & $24,667.2$ & 38.1439 & 146.55 & 29.25 & \\
\hline & (5) $600<$ & 197,534 & $15,623.0$ & 24.1585 & 323.83 & 64.64 & \\
\hline \multicolumn{7}{|l|}{ Wind effect } & \multirow{5}{*}{$\begin{array}{l}\text { ASTER } \\
\text { DEM \& } \\
\text { SMOAC }\end{array}$} \\
\hline & (1) $0.73-0.93$ & 203,575 & $16,100.8$ & 24.9279 & 161.16 & 32.25 & \\
\hline & (2) $0.93-1.09$ & 204,281 & $16,156.7$ & 25.0143 & 143.42 & 28.62 & \\
\hline & (3) $1.09-1.25$ & 204,979 & $16,211.9$ & 25.0998 & 123.72 & 24.69 & \\
\hline & (4) $1.25-1.35$ & 203,820 & $16,120.2$ & 24.9579 & 72.25 & 14.42 & \\
\hline \multirow[t]{4}{*}{$\begin{array}{c}\text { Plan curvature } \\
(100 / \mathrm{m})\end{array}$} & & & & & & & \multirow{4}{*}{$\begin{array}{c}\text { ASTER } \\
\text { DEM }\end{array}$} \\
\hline & (1) Concave & 153,099 & $12,108.7$ & 18.73 & 62.9 & 12.55 & \\
\hline & (2) Flat & 499,095 & $39,473.7$ & 61.05 & 351.45 & 70.15 & \\
\hline & (3) Convex & 165,204 & 13,066 & 20.21 & 86.59 & 17.28 & \\
\hline \multirow[t]{6}{*}{$\begin{array}{c}\text { Topographic } \\
\text { wetness index } \\
\text { (TWI) }\end{array}$} & & & & & & & \multirow{6}{*}{$\begin{array}{c}\text { ASTER } \\
\text { DEM }\end{array}$} \\
\hline & (1) $5-10$ & 89,647 & 7090.23 & 10.97 & 61.82 & 12.34 & \\
\hline & (2) $10-15$ & 186,858 & $14,778.7$ & 22.8 & 117.62 & 23.48 & \\
\hline & (3) $15-20$ & 113,587 & 8983.66 & 13.9 & 61.22 & 12.22 & \\
\hline & (4) $20<$ & 259,476 & $20,522.1$ & 31.7 & 174.21 & 34.72 & \\
\hline & & 167,087 & 13,215 & 20.45 & 86.07 & 17.18 & \\
\hline
\end{tabular}


Table 1. Cont.

\begin{tabular}{|c|c|c|c|c|c|c|c|}
\hline Factors & Class & $\begin{array}{l}\text { \# of Pixels in } \\
\text { Domain }\end{array}$ & Area (ha) & $\begin{array}{c}\% \text { of } \\
\text { Domain }\end{array}$ & $\begin{array}{l}\text { Area of Forest } \\
\text { Fires (ha) }\end{array}$ & $\begin{array}{c}\% \text { of Forest } \\
\text { Fires }\end{array}$ & Source \\
\hline \multicolumn{8}{|c|}{ Landform } \\
\hline & (1) canyon & 39,975 & 3161.64 & 4.8 & 16.10 & 3.21 & \multirow{4}{*}{$\begin{array}{c}\text { ASTER } \\
\text { DEM }\end{array}$} \\
\hline & (2) Gentle slopes & 159,331 & $12,601.5$ & 19.48 & 63.23 & 12.62 & \\
\hline & (3) steep slope & 513,481 & $40,611.5$ & 62.79 & 375.23 & 75.02 & \\
\hline & (4) ridges & 104,869 & 8294.15 & 12.825 & 45.75 & 9.13 & \\
\hline \multicolumn{7}{|l|}{ Land use } & \multirow{5}{*}{$\begin{array}{l}\text { LANDSAT } \\
\text { satellite } \\
\text { image }\end{array}$} \\
\hline & (1) Forest & 748,822 & $59,224.8$ & 91.4729 & 491.8 & 98.03 & \\
\hline & (2) Non-forest & 56,744 & 4487.91 & 6.93160 & 9.87 & 1.97 & \\
\hline & (3) Farm & 10,619 & 839.863 & 1.29717 & 0 & 0 & \\
\hline & (4) village & 2442 & 193.139 & 0.29830 & 0 & 0 & \\
\hline \multicolumn{7}{|l|}{ NDVI } & \multirow{6}{*}{$\begin{array}{c}\text { LANDSAT } \\
8\end{array}$} \\
\hline & (1) $-0.08-0.1$ & 162,431 & $12,846.7$ & 19.86 & 38.03 & 7.59 & \\
\hline & (2) $0.1-0.36$ & 153,261 & $12,121.5$ & 18.74 & 72.30 & 14.44 & \\
\hline & (3) $0.36-0.41$ & 161,025 & $12,735.5$ & 19.69 & 103.78 & 20.73 & \\
\hline & (4) $0.41-0.43$ & 176,758 & $13,979.9$ & 21.617 & 160.03 & 31.94 & \\
\hline & (5) $0.43<$ & 164,181 & $12,985.1$ & 20.07 & 121.70 & 25.29 & \\
\hline \multicolumn{7}{|c|}{$\begin{array}{l}\text { Distance to } \\
\text { stream (m) }\end{array}$} & \multirow{6}{*}{$\begin{array}{l}\text { ASTER } \\
\text { DEM }\end{array}$} \\
\hline & (1) $200>$ & 78,797 & 6232.1 & 9.636 & 22.56 & 4.5 & \\
\hline & (2) $200-500$ & 106,507 & 8423.7 & 13.02 & 83.04 & 16.57 & \\
\hline & (3)500-800 & 106,173 & 8397.2 & 12.985 & 97.99 & 19.57 & \\
\hline & (4) $800-1200$ & 131,936 & $10,434.9$ & 16.135 & 67.93 & 13.56 & \\
\hline & $(5) 1200<$ & 394,243 & $31,180.93$ & 48.216 & 229.43 & 45.79 & \\
\hline \multicolumn{7}{|c|}{$\begin{array}{l}\text { Distance to road } \\
(\mathrm{m})\end{array}$} & \multirow{6}{*}{$\begin{array}{c}\text { SWOAC } \\
\text { [52] }\end{array}$} \\
\hline & (1) 0-300 & 141,880 & $11,221.3$ & 17.352 & 115.99 & 23.15 & \\
\hline & (2) 300-600 & 116,931 & 9248.14 & 14.30 & 107.178 & 21.49 & \\
\hline & (3) $600-1200$ & 172,493 & $13,642.5$ & 21.096 & 99.06 & 19.77 & \\
\hline & (4) $1200-1800$ & 129,926 & $10,275.9$ & 15.890 & 88.82 & 17.73 & \\
\hline & (5) $1800<$ & 256,426 & $20,280.9$ & 31.36 & 89.40 & 17.78 & \\
\hline \multicolumn{7}{|c|}{$\begin{array}{c}\text { Recreation area } \\
(\mathrm{m})\end{array}$} & \multirow{4}{*}{$\begin{array}{c}\text { SWOAC } \\
\text { [52] }\end{array}$} \\
\hline & (1) $0-300$ & 32,430 & 2689.05 & 3.881 & 13.87 & 2.77 & \\
\hline & (2) $300-700$ & 72,251 & 5985.99 & 9.006 & 0.098 & 0.019 & \\
\hline & (3) $700<$ & 751,341 & $59,830.23$ & 87.021 & 468.21 & 97.20 & \\
\hline \multicolumn{7}{|c|}{$\begin{array}{l}\text { Potential solar } \\
\text { radiation }\end{array}$} & \multirow{6}{*}{$\begin{array}{l}\text { SWOAC } \\
\text { [52] }\end{array}$} \\
\hline & $\begin{array}{c}(1) \\
282.943-983.084\end{array}$ & 64,516 & 5102.61 & 7.89 & 98.04 & 3.9 & \\
\hline & $\begin{array}{c}(2) \\
983.084-1.189 .376\end{array}$ & 21,641 & 1711.60 & 2.646 & 1.26 & 0.25 & \\
\hline & $\begin{array}{c}(3) \\
1.189 .376-1.339 .406\end{array}$ & 54,780 & 4332.58 & 6.699 & 2.47 & 0.49 & \\
\hline & $\begin{array}{c}(4) \\
1.339 .406-1.501 .939\end{array}$ & 113,723 & 8994.4 & 13.90 & 59.65 & 11.9 & \\
\hline & $\begin{array}{c}(5) \\
1.501 .939-1.877 .015\end{array}$ & 562,996 & $44,527.71$ & 68.85 & 339.51 & 67.71 & \\
\hline \multicolumn{7}{|c|}{$\begin{array}{l}\text { Distance to } \\
\text { village (m) }\end{array}$} & \multirow{6}{*}{$\begin{array}{c}\text { SWOAC } \\
\text { [52] }\end{array}$} \\
\hline & (1) $0-300$ & 33,175 & 2623.83 & 4.05 & 0.094 & 0.018 & \\
\hline & (2) 300-600 & 33,140 & 2621.06 & 4.053 & 13.85 & 2.76 & \\
\hline & (3) 600-1200 & 82,832 & 6551.23 & 10.13 & 16.99 & 3.39 & \\
\hline & (4) $1200-2400$ & 203,181 & $16,069.71$ & 24.84 & 73.72 & 14.71 & \\
\hline & (5) $2400>$ & 465,328 & $36,803.0$ & 56.90 & 396.28 & 79.1 & \\
\hline
\end{tabular}

Acronyms stand for: the state wildlife organization of Amol County (SWOAC) [52], the state meteorological organization of Amol County (SMOAC) [53]. (ASTER DEM) The advanced spaceborne thermal emission and reflection radiometer (ASTER) onboard the national aeronautics and space administration's (NASA's) Terra spacecraft provides digital elevation model (DEM) [54]. 

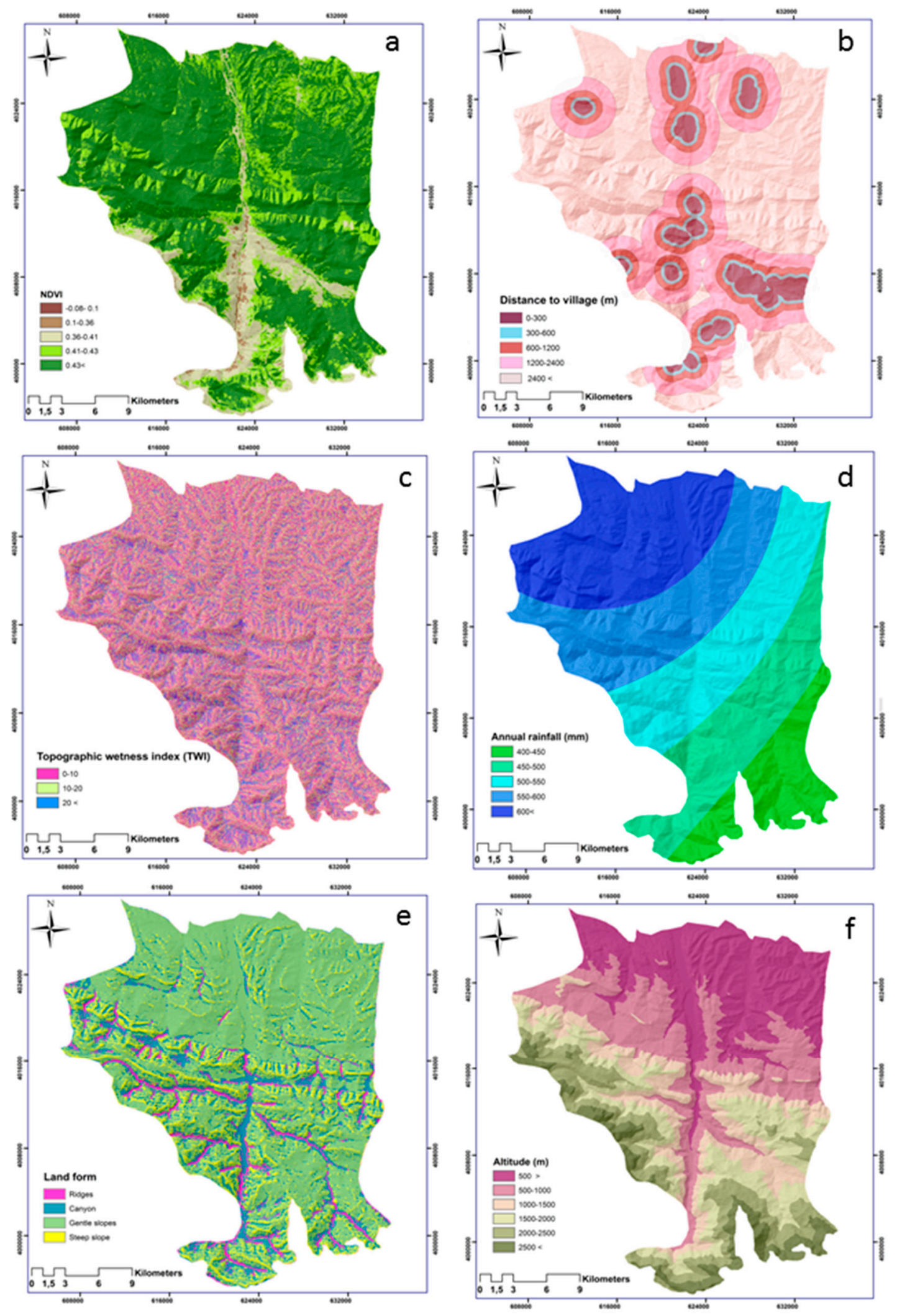

Figure 3. Cont. 

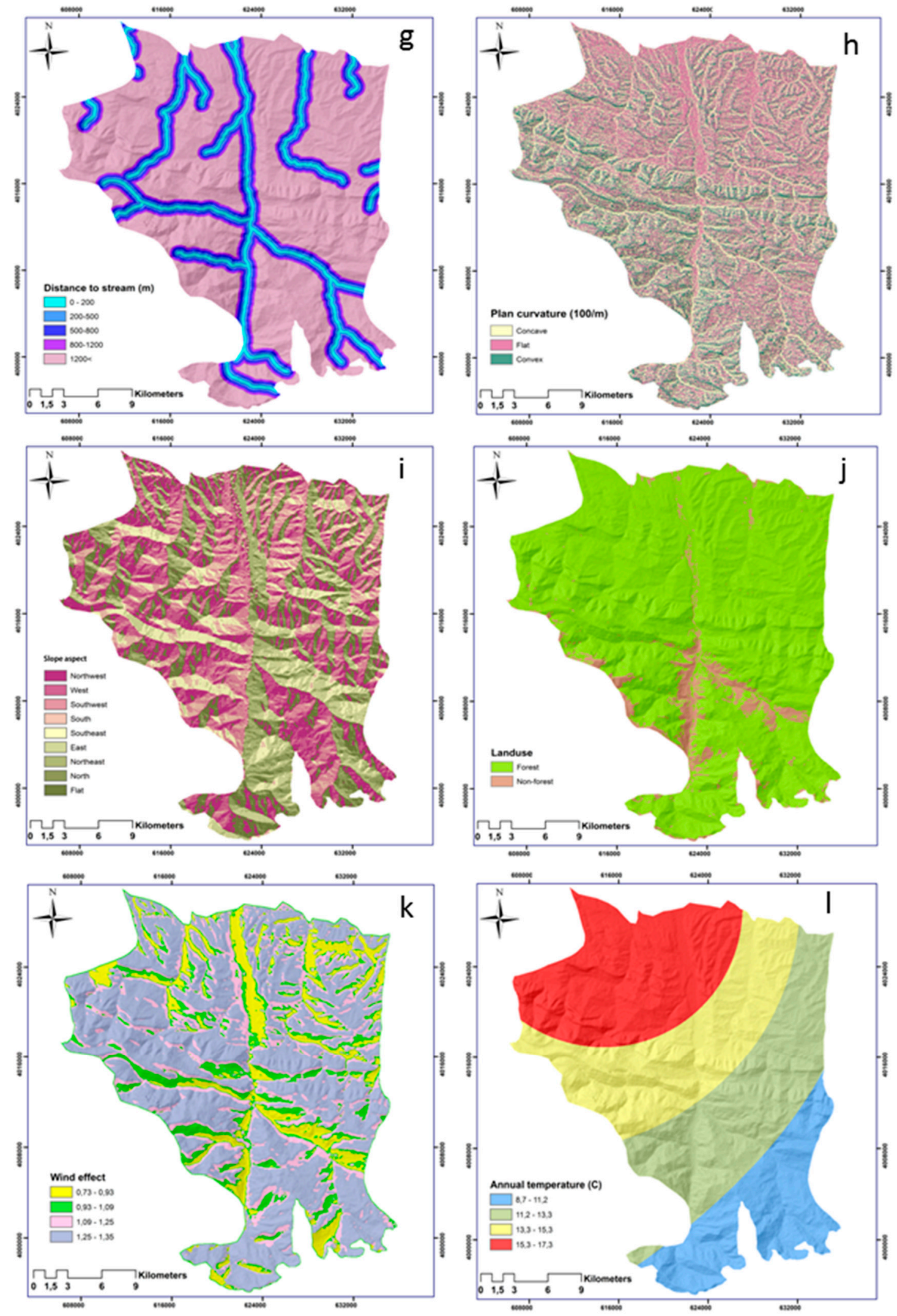

Figure 3. Cont. 

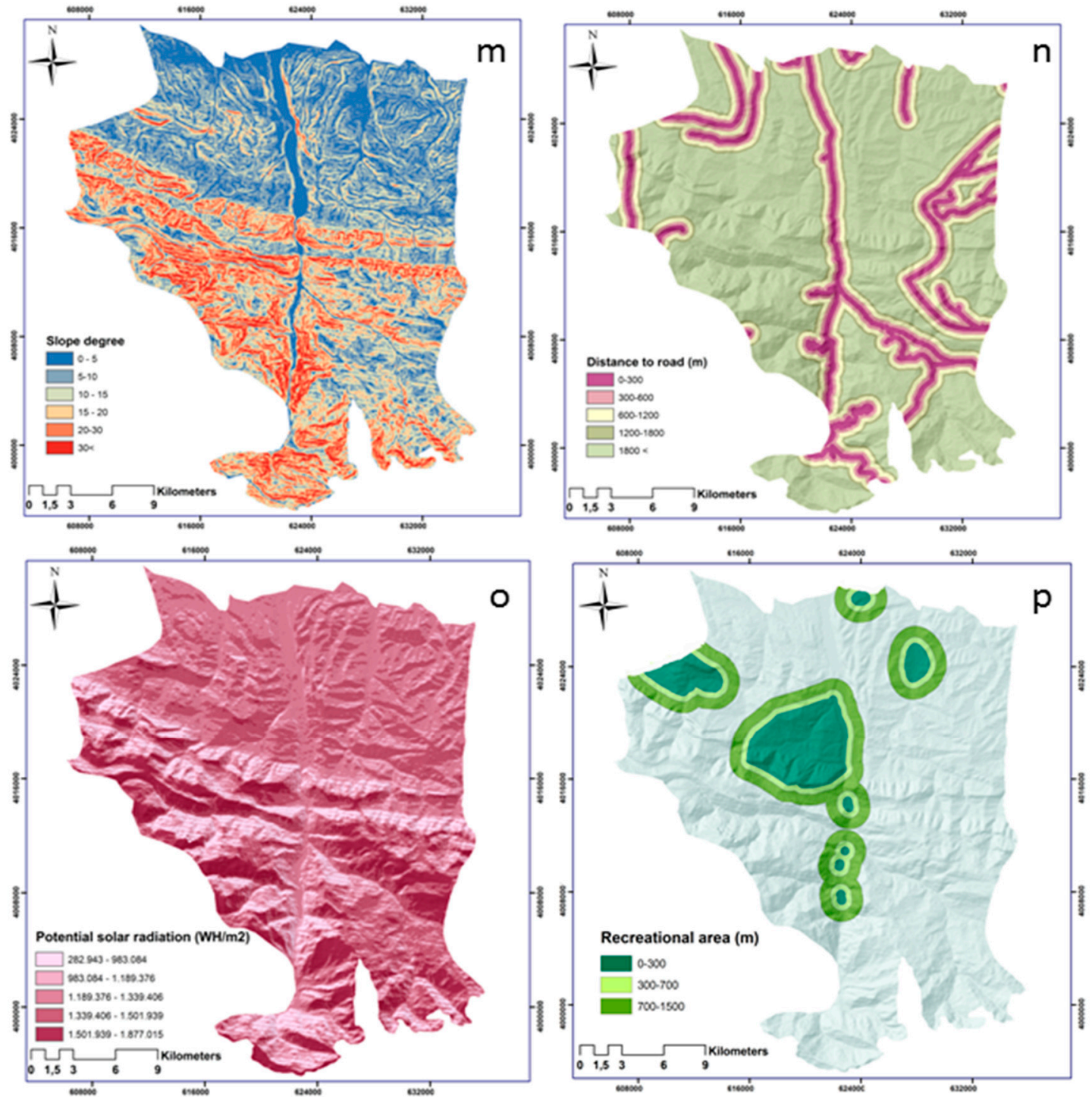

Figure 3. Sixteen input forest fire factors used in the artificial neural network (ANN) method: (a) normalized difference vegetation index (NDVI), (b) distance to village, (c) topographic wetness index (TWI), (d) annual rainfall, (e) land form, (f) altitude, (g) distance to stream, (h) plan curvature, (i) slope aspect, (j) land use, (k) wind effect, (l) annual temperature, (m) slope degree, (n) distance to road, $(\mathbf{o})$ potential solar radiation, $(\mathbf{p})$ recreational areas.

\subsection{Data Generation for Training and Testing}

In this subsection, we summarise the generation process of our training and test data. The polygons of the forest fires in the study area were generated based on GPS data (obtained from the state wildlife organization) along with the hotspots of Moderate Resolution Imaging Spectroradiometer (MODIS) (NASA, Goddard Space Flight Center, Maryland, USA). Using MODIS fire detection data is common, and used in several current studies, to specify the location and the time of forest fires [55-57]. Our investigation resulted in 34 forest fire GPS polygons that were evaluated by the MODIS sensor during the 2012-2017 timeframe (see Figure 1). Of these forest fire polygons, we randomly selected $70 \%$ (12,195 pixels) as training data and 30\% (5226 pixels) for the validation section using ten-fold cross-validation (CV) (see Figure 4). We used the ten-fold CV approach to deal with the randomness adverse effects on the forest fire susceptibility modelling [58]. The forest fire polygons were randomly divided into ten folds of approximately 1742 pixels. Technically speaking, if we have the dataset $D$ and divide it randomly into $k$ number of the same folds of $D_{1}, D_{2}, \ldots, D_{k}$. Then, the model is trained $k$ times 
and each time $t \in(1,2, \ldots, k)$. For the time of $t$, the model is run with the dataset of $D$ lacking of the subset of $D_{t}$, and validated with $D_{t}$ [59]. Thus, three of the folds were chosen each time for validation and other seven folds were used for training the model. This process was repeated for every fold in our inventory dataset of the forest fire. Although most researchers used ten folds, the number of folds in the spatial applications is often selected by the user without any empirical evidence. The authors of Reference [60] used a three-fold CV approach. Whereas, in Reference [61] they selected a five-fold for their training and validation aims. We selected ten folds for the cross validation because of the large volume of our inventory dataset. Therefore, the outputs of the forest fire susceptibility modelling in this study were based on the ten-fold CV that resulted in the highest accuracies in both the training and the validation sections (see Sections 3.1 and 4.1).

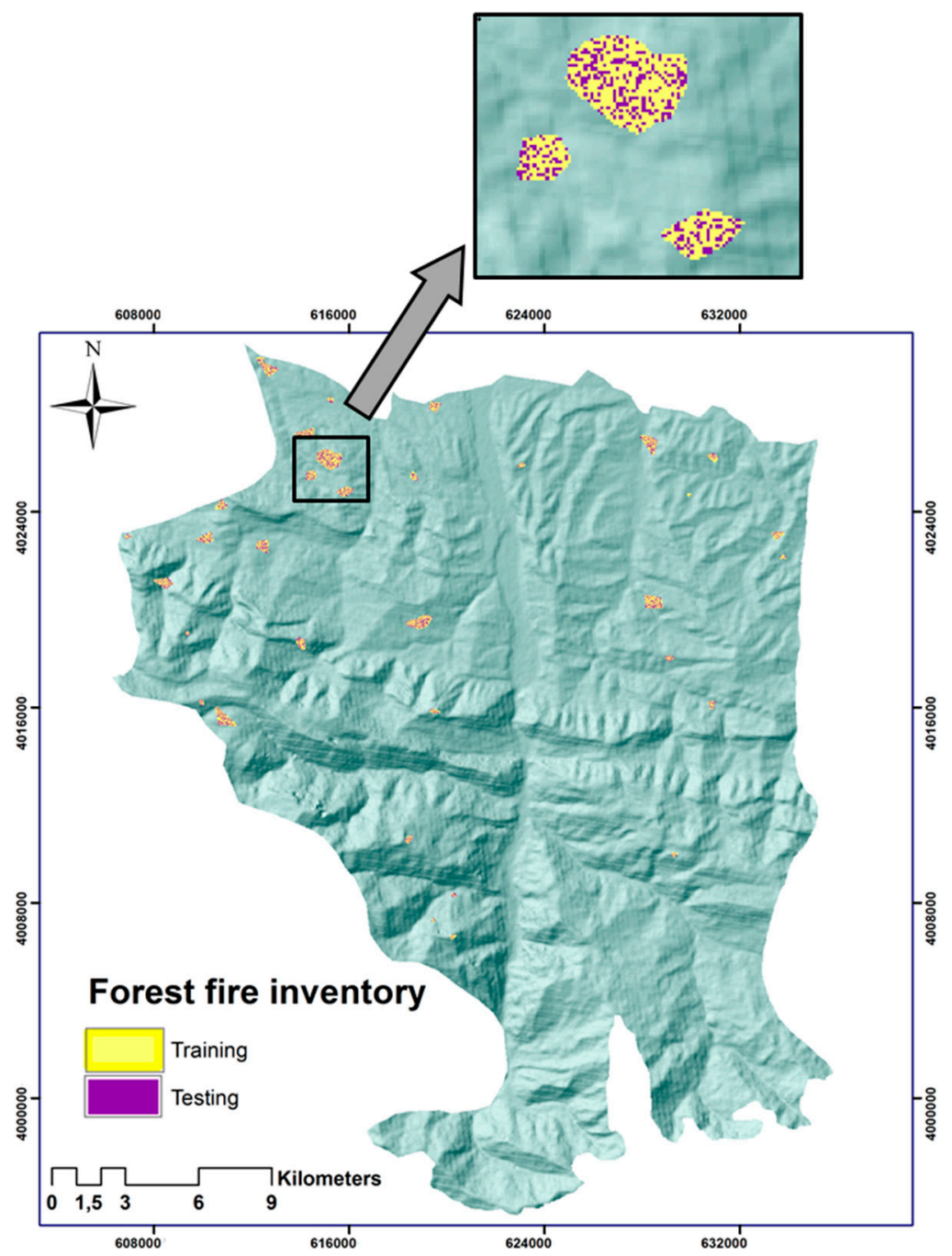

Figure 4. Forest fire inventory divided randomly to training and testing.

\section{Workflow}

\subsection{Forest Fire Susceptibility Mapping Using Artificial Neural Network (ANN)}

The ANN method is considered to be one of the most commonly used ML methods to assess susceptible areas of forest fires [28]. Generally, ANNs mimic human brain performance, and they can solve complex nonlinear problems with multiple numbers of components and variables [62]. ANNs also can find patterns and discover the trends of complex issues [63]. In the present study, to create an index for assessing forest fires, a model was used with the ANN method using a multilayer perceptron (MLP) 
architecture and trained with the backpropagation algorithm (BPA), which is considered as the most common algorithm for the ANN method. The MLP architecture consists of several hidden layers between the input and output layers. The number of hidden layers of a neural network depends on the complexity of the problem [64]. For our case, the feed-forward network was made up of an input layer with 16 neurons (input factors), one hidden layer (28 neurons) and one output layer as a network structure of 16-28-1 (see Figure 5). The number of 28 hidden layers was determined through 3-fold CV on a range of $(12,18,28$ neurons).

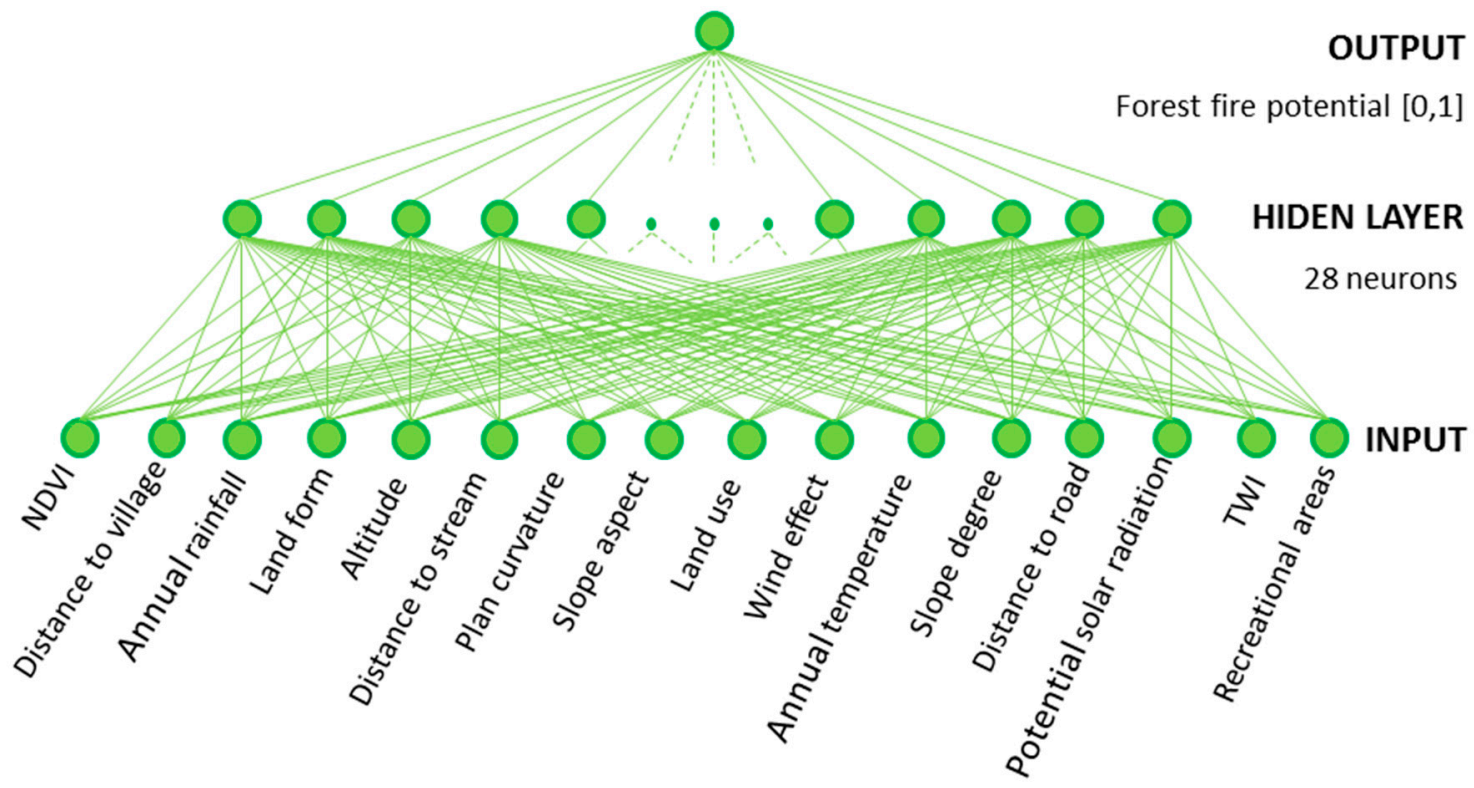

Figure 5. The architecture of the neural network model for Forest fire.

The training dataset consists of forest fire and non-forest fire areas containing sixteen inputs, namely, slope aspect, slope degree, altitude, plan curvature, landform, TWI, annual temperature, potential solar radiation, wind effect, NDVI, distance to village, land use, distance to road, recreational areas, annual rainfall, and distance to stream. Mapping forest fire susceptibility using the described ANN method consists of a three-stage process, namely, training, allocation, and testing the values of each pixel of an input layer were presented to the neural network along with the values of the training dataset. Each of the fifteen neurons in the input layer $\left(y_{1}, y_{2}, \ldots, y_{16}\right)$ characterized an attribute of the input data and transferred the signal to the corresponding connected neurons $\left(z_{1}, z_{2}, \ldots, z_{9}\right)$ in our hidden layer. The total input signal to the $z_{x}$ neuron (in the hidden layer) can be defined as Equation (1) [65].

$$
z(i n)_{x}=\sum_{1}^{16} u_{i x} y_{i}+u_{x}
$$

where, $u_{i x}$ is the weighted value that came from the $i^{\text {th }}$ input neuron and $u_{x}$ is the corresponding bias value. The activation of each neuron in this layer is computed separately and transferred to the next neuron, which is the output neuron. Equation (2) presents how the output neuron $O$ catches the values from the hidden layer.

$$
O(\text { in })=\sum_{1}^{28} z_{j} w_{j}+w_{o}
$$

where, $z_{j}$ is the $j^{\text {th }}$ resulting value from Equation (1), $w_{j}$ is the weight and $w_{0}$ is the corresponding bias value [66]. The calculated output value from the ANN method is compared with the forest fire pixel values, which are considered as the target value $t$. The comparison is done for every terrain unit until the overall error between $t$ and the derived output value $o$ is acceptable (minimum). The forest fire pixel 
values, which are considered as the target value $t$, were not used for training data earlier in the process. The momentum parameter avoids divergence during the process, and has a useful role in increasing the speed of convergence [67]. All weightings were updated by the backward process during each cycle in order to minimize the error. The common activation functions used for the ANN method are hyperbolic tangent and the logistic functions. For our case, the logistic function (see Equation (3)) was selected, as the output of the function is an interval value varying from 0 to 1 , which is more preferable for a susceptibility map.

$$
\mathrm{f}\left(x_{i}\right)=\left(1+e^{-x_{i}}\right)^{-1}
$$

The transfer function $\mathrm{f}$ was a nonlinear sigmoid function that was used to the weighted sum of the input data before the next layer. Different learning rates were applied from 0.1 to 0.9 and the learning rate of 0.9 got a higher accuracy in forest fire susceptibility mapping. Several iterations were tested, and 1000 iterations were selected as the optimal one in terms of both of accuracy and cost. Finally, the hazard map was generated from the output values of the ANN method. The pixels with values close to 1 have a higher probability of forest fires occurring and pixels with low values indicate safer areas.

\subsection{Social/Infrastructural Vulnerability Indexes}

\section{Choice of Indicators}

There are several social indicators, such as education level, age, gender, and access to government facilities and health services, that can indicate the level of a community's ability to be deal with and recover from natural hazards like forest fires [18,38]. In this research, 22 social vulnerability indicators were selected based on the living standards and local conditions in our study area (see Table 3). The dataset was obtained from the Iranian Bureau of Statistics 2017 census. Our study area consists of 20 villages with an estimated population of 2887. The least populated village only has 11 inhabitants, and the most populated one has a population exceeding 1650 . Since all villages belong to the same county, they have approximately equal access to government support and facilities. However, there are some indicators that vary between villages, e.g., the percent of the vulnerable population under 14 years of age or 65 and older, and the percent of the unemployed people.

In this study, we also consider several susceptible areas and valued infrastructural assets and resources within the study area that are prone to forest fires (see Table 4). There are also some people who live temporarily (seasonal) or permanently in these areas. Roads and forest parks, for instance, are frequented by visitors from all over the country and, mainly, from Tehran during the summer time. On the other hand, since the occupation of most people in our study area is the livestock sector, there are several barns in the depths of the forest areas, most of which are illegal. These barns are used to keep the livestock during the fall and winter. As they are usually established in remote areas, it is more likely that they are surrounded by or even engulfed in a fire during a forest fire event. Thus, eleven infrastructural vulnerability indicators were also selected based on the situation of our study area. To consider the spatial information of both the social and infrastructure indicators, the datasets need to be transferred to a GIS environment and aggregated to layers. However, the indicators are represented by different measurement scales (i.e., percentage and number) [68]. Thus, before being aggregated, they were transformed into a continuous scale of common units with a linear standardisation method.

\subsection{Aggregation of Different Indicators Using Geographic Information System Multi-Criteria Decision Making (GIS-MCDM)}

A GIS-MCDA [69] approach was used to account for the relative significance of each indicator regarding forest fires in our study area. The weightings of social vulnerability and infrastructure vulnerability were calculated separately. If all of the indicators are believed to have the same importance, an equal weighting value should be used to obtain the total vulnerability [16]. Although different indicators (e.g., age, employment and education) might have approximately equal importance when 
we consider the general context of vulnerability, their significance depends on the type of natural hazard. MCDAs are practical approaches for a wide range of complex decision-making systems.

The set of $X=\left(x_{1}, x_{2}, \ldots, x_{n}\right)$ was considered with $n$ number of selected social indicators. Experts compared each pair of indicators $\left(x_{i}\right.$ and $\left.x_{j}\right)$ in $X$. A value $\left(a_{i j}\right)$ can also result from the ratio of their weightings [70]. If the social indicator $x_{i}$ is preferred to $x_{j}$, then $a_{i j}>1$ and, conversely, if $x_{j}$ is preferred to $x_{i}$ then $a_{i j}<1$. A verbal description of the importance, introduced by Saaty to compare various indicators in a pairwise manner, is given in Table 2 . The values vary from 1 , for equal importance, to 9 , for extreme importance. For $i$ and $j=1,2, \ldots, \mathrm{n}$, and any $a_{i j}>0$ we have $a_{j i}=\frac{1}{a_{i j}}$ (reciprocal property). The resulting indicator weightings $\left(\mathrm{w}_{1}, \mathrm{w}_{2}, \mathrm{w}_{3}, \ldots, \mathrm{w}_{\mathrm{n}}\right)$ have two conditions, namely: $0 \leq w_{k} \leq 1$ and $\sum_{k=1}^{n} w_{k}=1$

Therefore, the pairwise comparisons are structured in a matrix, and the matrix's elements are between $1 / 9$ and 9. The AHP method can integrate both quantitative and qualitative dimensions of a decision-making problem [71]. The method is also able to differentiate between our indicators and to support the comparison of the performance of them with few calculations [72].

$$
\left[\begin{array}{cccccccccc}
1 & a_{12} & \ldots & & a_{1 i} & \ldots & a_{1 j} & \ldots & a_{1 n} & \\
\frac{1}{a_{12}} & 1 & \ldots & & a_{2 i} & \ldots & a_{2 j} & \ldots & a_{2 n} & \\
\ldots & \ldots & 1 & & \ldots & \ldots & \ldots & \ldots & \ldots & \\
\frac{1}{a_{1 i}} & \frac{1}{a_{2 i}} & \ldots & 1 & \ldots & a_{i j} & \ldots & a_{i n} \\
\ldots & \ldots & \ldots & \ldots & 1 & \ldots & \ldots & \ldots \\
\frac{1}{a_{1 j}} & \frac{1}{a_{2 j}} & \ldots & \frac{1}{a_{i j}} & \ldots & 1 & \ldots & a_{j n} \\
\ldots & \ldots & \ldots & \ldots & \ldots & \ldots & & 1 & \ldots \\
\frac{1}{a_{1 n}} & \frac{1}{a_{2 n}} & \ldots & \frac{1}{a_{i n}} & \ldots & \frac{1}{a_{j n}} & \ldots & 1
\end{array}\right]
$$

Table 2. The scale of Intensity of Importance (IOI) [73].

\begin{tabular}{cc}
\hline IOI & Description \\
\hline 1 & Equal importance \\
3 & Moderate importance \\
5 & Strong or essential importance \\
7 & Very strong or demonstrated \\
9 & importance \\
$2,4,6,8$ & Extreme importance \\
Reciprocals & Intermediate values \\
\hline
\end{tabular}

If $\lambda_{\max }$ is the maximum eigenvalue, the consistency ratio (CR) of the resulting weightings is determined by $C R=\lambda_{\max }-n / R I(n-1)$ [74]. Where $R I$ is the average random index, which for $n=$ $2,3,4,5,6,7$ and $8, R I=0.00,0.52,0.89,1.11,1.25,1.35$ and 1.40 , respectively. A $C R<0.10$ indicates an acceptable consistency throughout the whole AHP process $[75,76]$. Using this process, we calculated the pairwise comparison matrices for the decisions of our chosen field experts, who represented the national university, the state wildlife organization, and the meteorological organization (their names and affiliations are mentioned in the acknowledgments). Both the comparison matrices of social vulnerability and infrastructure vulnerability passed the consistency test with overall $C R$ scores of 0.055 and 0.024 , respectively. Weightings are shown in the last column of Tables 3 and 4. 
Table 3. Social vulnerability indicators and resulting analytic hierarchy process (AHP) weights for each indicator.

\begin{tabular}{|c|c|c|}
\hline Indicators & Sub-Indicators & AHP Weights \\
\hline \multicolumn{3}{|l|}{ Education } \\
\hline & $\begin{array}{c}\text { Speaking the official language (Persian) as a second language with limited } \\
\text { Persian proficiency }(\%)\end{array}$ & 0.045 \\
\hline & $\begin{array}{l}\text { Population that does not have any level of formal education or instruction } \\
\qquad(\%)\end{array}$ & 0.051 \\
\hline & Population that does not have access to school $\backslash$ high school (\%) & 0.040 \\
\hline \multicolumn{3}{|l|}{ Housing } \\
\hline & Houses older than ten years (\%) & 0.041 \\
\hline & Houses without steel or concrete skeleton (\%) & 0.059 \\
\hline & Houses with an area less than $75(\%)$ & 0.007 \\
\hline & Houses without garbage collection service (\%) & 0.006 \\
\hline \multicolumn{3}{|l|}{ Age } \\
\hline & Population under 14 years or 65 and older (\%) & 0.064 \\
\hline \multicolumn{3}{|l|}{ Female } \\
\hline & Female population (\%) & 0.035 \\
\hline & Female-headed households (\%) & 0.047 \\
\hline \multicolumn{3}{|l|}{ Health services } \\
\hline & The population that does not have access to health centres (\%) & 0.072 \\
\hline & The population that does not have access to a family doctor (\%) & 0.021 \\
\hline & The population that does not have access to a lab and pharmacy (\%) & 0.025 \\
\hline \multicolumn{3}{|l|}{ Facilities } \\
\hline & Households without access to the public electricity network (\%) & 0.073 \\
\hline & Households without access to drinking water from the public system (\%) & 0.050 \\
\hline & Households without access to the public gas pipeline network (\%) & 0.033 \\
\hline & Households without access to the sewerage system (\%) & 0.007 \\
\hline & Households without access to the internet network (\%) & 0.034 \\
\hline & $\begin{array}{l}\text { The population that does not have access to the public transportation } \\
\text { system (\%) }\end{array}$ & 0.012 \\
\hline & Fire station & 0.201 \\
\hline & Police station & 0.034 \\
\hline \multicolumn{3}{|l|}{ Occupation } \\
\hline & Unemployed population (\%) & 0.040 \\
\hline
\end{tabular}

Table 4. Infrastructural vulnerability indicators and resulting AHP weights for each indicator. All distances measures are based on meters.

\begin{tabular}{|c|c|c|}
\hline Indicators & Sub-Indicators & AHP Weights \\
\hline \multicolumn{3}{|l|}{ Industrial area } \\
\hline & Mines & 0.033 \\
\hline & Livestock and poultry farming (nests) & 0.242 \\
\hline & The national power line & 0.035 \\
\hline \multicolumn{3}{|l|}{ Recreational area } \\
\hline & $\begin{array}{l}\text { Forest parks with some amenities such as shelters for } \\
\text { temporary stays in the woods }\end{array}$ & 0.103 \\
\hline & Restaurants and buffets & 0.067 \\
\hline & Motels and Inns & 0.095 \\
\hline \multicolumn{3}{|l|}{ Roads } \\
\hline & $\begin{array}{l}\text { The main road from Tehran to northern Iran mainly } \\
\text { used for transporting essential goods and tourists }\end{array}$ & 0.060 \\
\hline & $\begin{array}{c}\text { Gravel roads mainly used by the local population } \\
\text { and illegal hunters }\end{array}$ & 0.041 \\
\hline \multicolumn{3}{|l|}{ Agricultural area } \\
\hline & Orchards, including walnut and apple gardens & 0.136 \\
\hline & Irrigated agriculture & 0.088 \\
\hline & Rain-fed agriculture mainly wheat and barley & 0.097 \\
\hline
\end{tabular}




\section{Results}

\subsection{The Predictive Performances and Resulting Hazard Map}

In this subsection, we sought to spatially represent regions on the study area associated with high susceptibility of forest fire. The ML component of the ANN method was used for susceptibility modelling and mapping. For this goal, the output values of the ANN method were derived through GIS spatial analysis and data aggregation models. As we trained the ANN method with burned area polygons which including also ignition locations, the resulting susceptibility maps represent a measure of the likelihood of ignition and the probability of spreading of forest fires based on considered conditioning factors. Figure 6 shows the results of the forest fire susceptibility map from the applied ML method. Concerning the spatial distribution, the probability of forest fires is higher in northern and central areas where local people and tourists have accessibility to low-elevation forests. The natural breaks classification method (or Jenks optimization) used in this study generates classes of similar values separated by breakpoints. This is a common and effective method for categorizing the susceptibility mapping results when we interpret values close to each class boundary (e.g., values between "Low" and "Moderate" probability) [77]. Table 5 depicts the area and the percentage of each class of the resulting forest fire map. The RMSE [78,79] was used to assess the model performance and Equation (5) depicts the calculation:

$$
\operatorname{RMSE}=\left(\frac{1}{N} \sum_{i=1}^{n}\left(e_{i}-\bar{e}_{i}\right)^{2}\right)^{0.5}
$$

where, $e_{i}$ and $\bar{e}_{i}$ are the $i^{\text {th }}$ observed and results of the ANN method, respectively. The best derived RMSE value based on the ten-fold CV was 0.145 . Generally, small values of the RMSE show better performance of the prediction model [80]. However, in order to validate the resulting forest fire susceptibility map, we conducted a validation process based on the 5226 forest fire pixels (see Section 2.3) that were not used for training in the utilized ANN method. The validation step aims to ensure the accuracy of the resulting hazard map [76]. The spatial success of the hazard map was examined through the receiver operating characteristics (ROC) curve, which is a common method for characterizing the quality of deterministic and probabilistic prediction methods. This curve shows the trade-off between the false positive rate and the true positive rate, by plotting the false positive rate on the $X$ axis and the true positive rate on the $\mathrm{Y}$ axis [24]. If the area under the curve (AUC) is close to one, this indicates that the prediction model has a high quality. Our ROC curve consists of 5226 pixels reflecting known and observed (by MODIS) forest fires in the study area. Figure 7 shows the results of comparing the observed forest fires with the forest fire susceptibility map. The results of the ROC method for our hazard map indicated accuracies fluctuate around $74 \%$ and the highest one based on the ten-fold CV was an accuracy of more than $80 \%$. This result was used to further analysis of the risk map generating. 


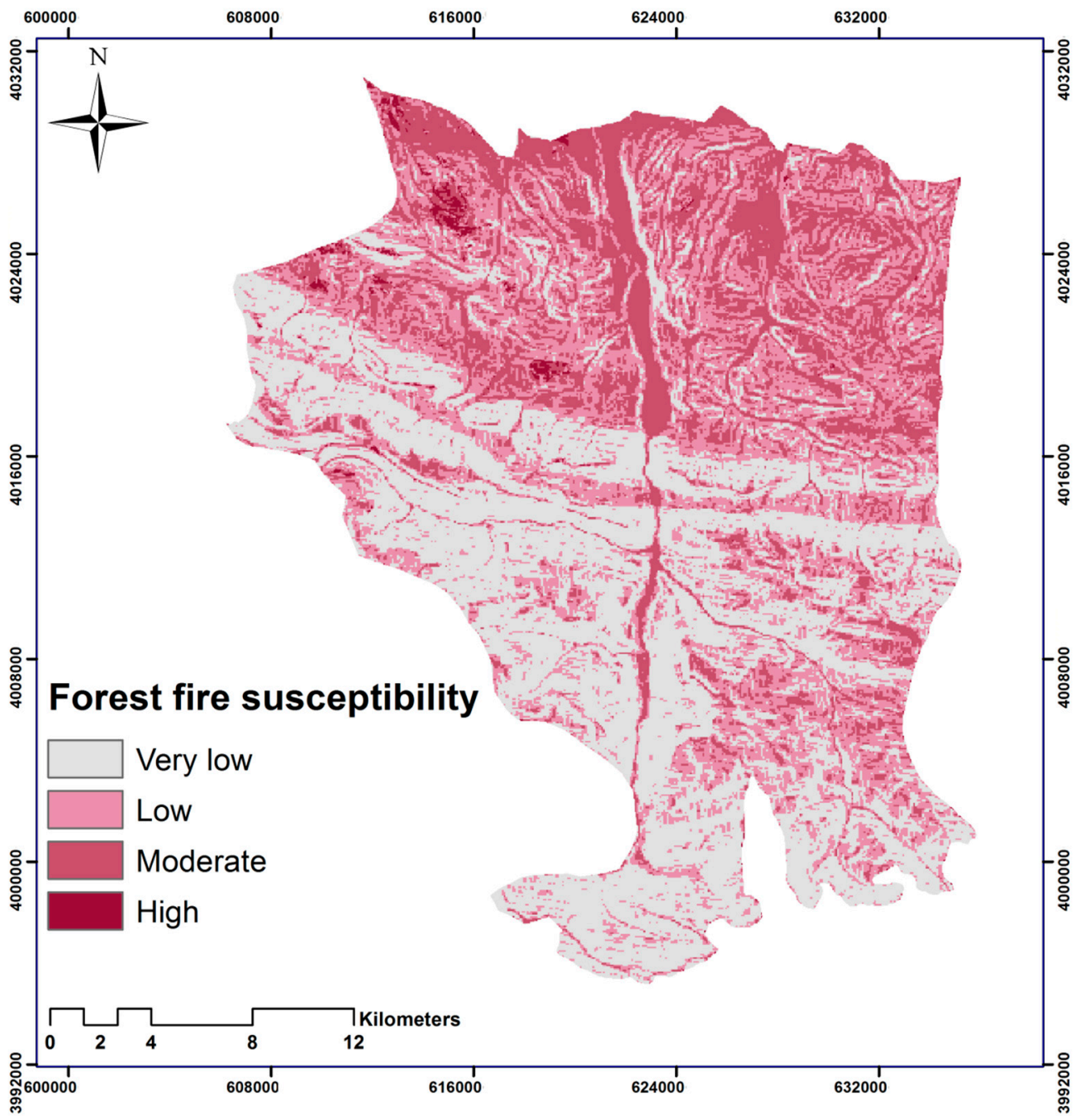

Figure 6. Forest fire susceptibility map.

Table 5. The AHP weights for the resulting maps and corresponding classes with the absolute area and the relative percentage of the region compared to the whole study area.

\begin{tabular}{|c|c|c|c|c|c|}
\hline Resulted Maps & AHP Weights & Classes & Area (ha) & Area (\%) & AHP Weights \\
\hline \multirow{5}{*}{$\begin{array}{c}\text { Forest fire } \\
\text { susceptibility }\end{array}$} & 0.53 & Very low & $26,665.96$ & 41.31 & 0.05 \\
\hline & & Low & $23,257.7$ & 36.03 & 0.08 \\
\hline & & Moderate & $14,399.16$ & 22.31 & 0.22 \\
\hline & & High & 215.28 & 0.33 & 0.64 \\
\hline & & & & & $C R=0.03$ \\
\hline \multirow{5}{*}{ Social vulnerability } & 0.29 & Very low & $62,998.69$ & 97.41 & 0.6 \\
\hline & & Low & 508.63 & 0.78 & 0.15 \\
\hline & & Moderate & 177.87 & 1.52 & 0.26 \\
\hline & & High & 983.73 & 2.27 & 0.42 \\
\hline & & & & & $\mathrm{CR}=0.03$ \\
\hline \multirow{5}{*}{$\begin{array}{l}\text { Infrastructural } \\
\text { vulnerability }\end{array}$} & 0.16 & Very low & $29,377.66$ & 45.43 & 0.078 \\
\hline & & Low & $28,688.23$ & 41.36 & 0.15 \\
\hline & & Moderate & 6445.09 & 9.96 & 0.26 \\
\hline & & High & 149.32 & 3.23 & 0.5 \\
\hline & $\mathrm{CR}=0.007$ & & & & $C R=0.005$ \\
\hline
\end{tabular}




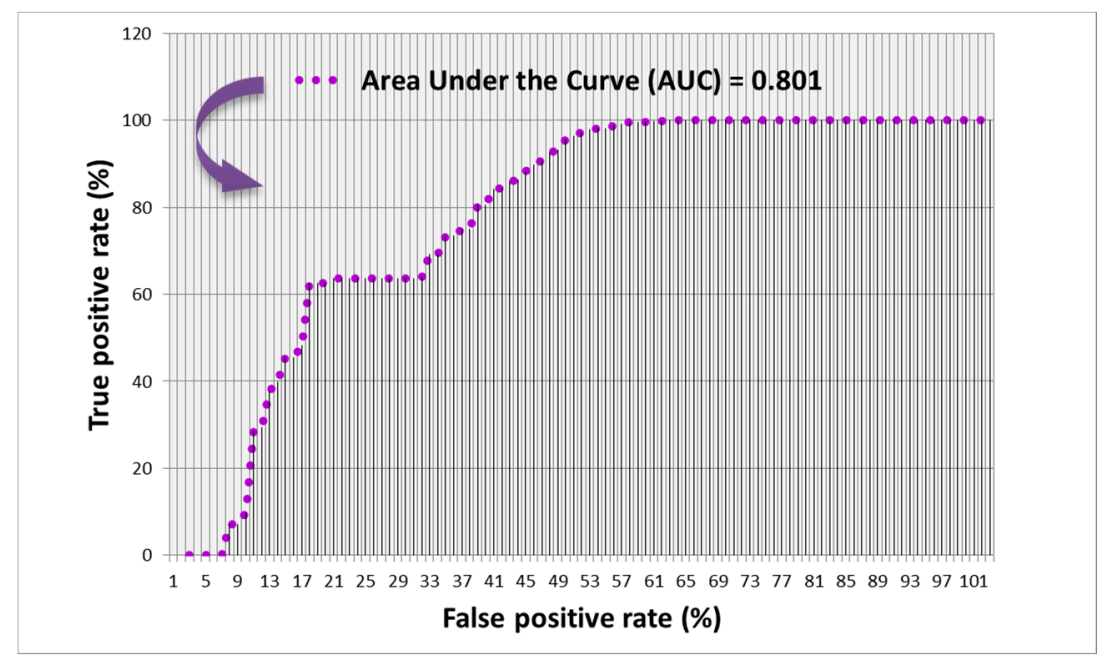

Figure 7. The receiver operating characteristics (ROC) curve and sensitivity value for the resulting hazard map.

\subsection{Social/Infrastructural Vulnerability Mapping}

To obtain social and infrastructural vulnerability maps, the weightings derived from the AHP method were used for data aggregation within a GIS environment. A buffer zone of $200 \mathrm{~m}$ was used for residential areas, and different multibuffers were used for infrastructural indicators based on their importance regarding forest fires. All indicators were prepared as GIS layers and then aggregated with a weighted overlay technique. Figure $8 \mathrm{a}$ and $\mathrm{b}$ present the vulnerability maps resulting from social and infrastructural indicators, respectively. The social vulnerability map was classified into five classes of vulnerability using the natural breaks classification method. The infrastructural vulnerability map, on the other hand, was classified into four categories of vulnerability using the same method of classification. The natural breaks classification method and the number of classes for categorisation were selected based on literature and expert knowledge. Table 5 shows the area of the respective classes for both the social and infrastructural vulnerability maps. 


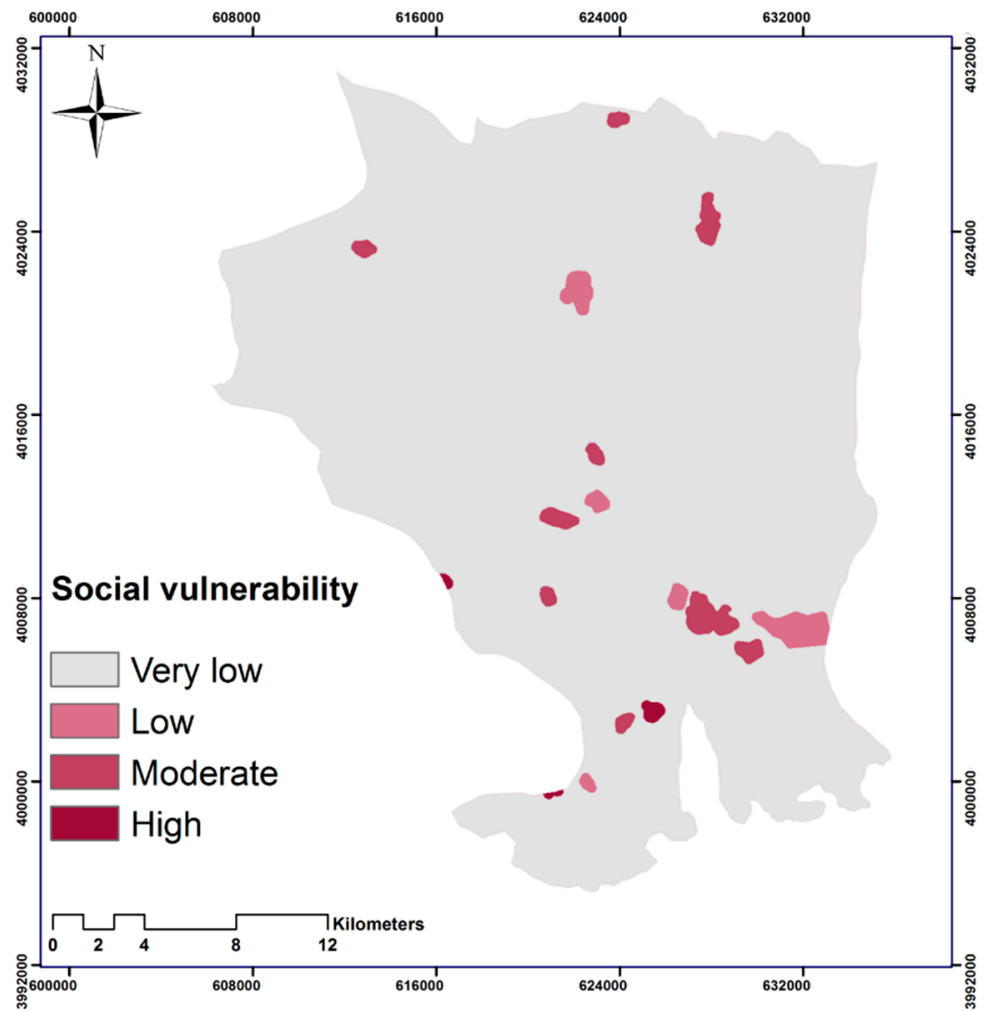

(a)

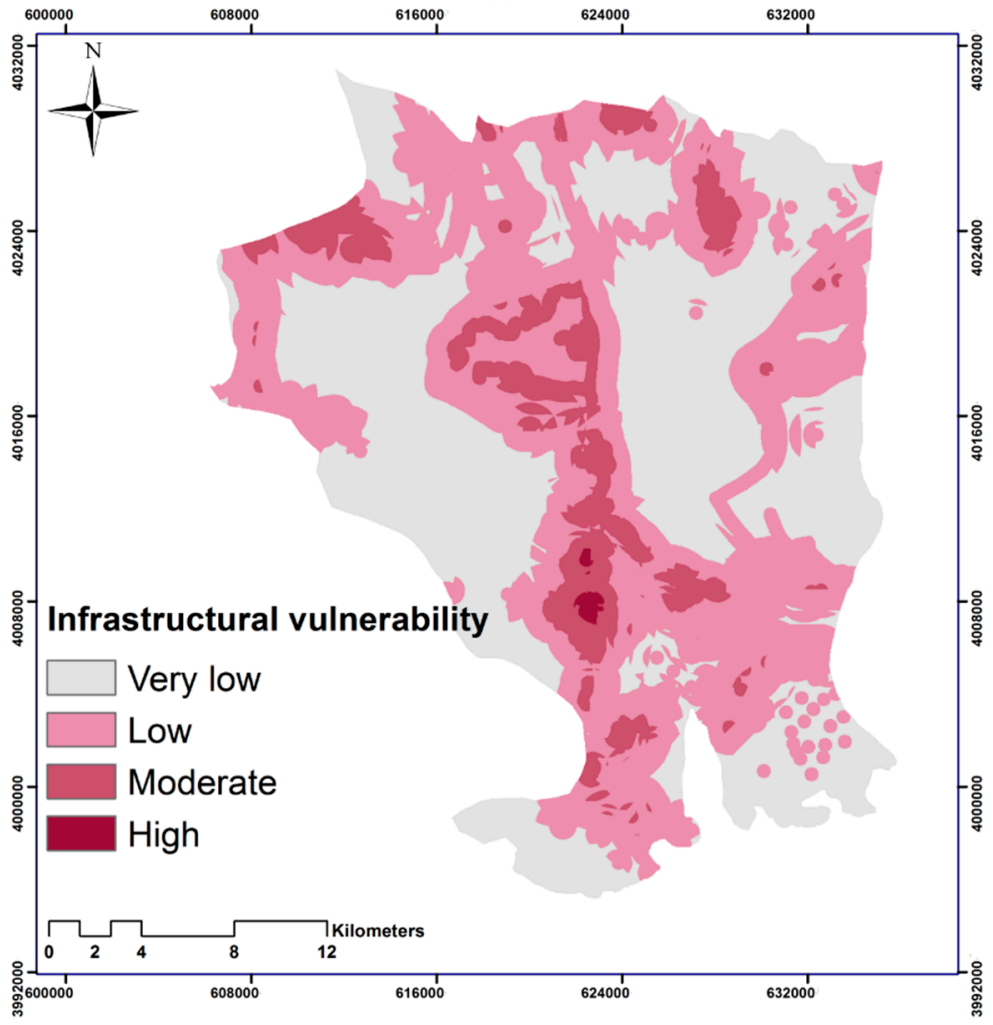

(b)

Figure 8. Resulting (a) infrastructural and (b) social vulnerability map. 


\subsection{Generation of the Risk Map}

Forest fires will have adverse impacts on different types of elements-at-risk. Thus, it is crucial to consider the forest fire threat for different sectors [9]. Moreover, all related stakeholders should be involved in a comprehensive forest fire risk mapping [81]. For this reason, we considered 16 relevant forest fire factors, 22 social vulnerability indicators, and 11 infrastructural indicators, to ensure the inclusion of the most important factors that play a role in the forest fire risk assessment in our study area. The hazard map was generated using an ANN method because we had access to sufficient inventory data for training and testing matters. However, social and infrastructural vulnerability maps were created using a GIS-MCDA method, which is one of the more common methods for vulnerability and susceptibility mapping in a wide range of disciplines [82]. Mapping areas with a high probability of forest fire risk can be carried out by aggregating the hazard map and the social/infrastructural vulnerability maps. The GIS-MCDA approach was, again, used to specify the relative significance of indicators and to aggregate the forest fire susceptibility, infrastructural vulnerability, and social vulnerability to generate the final risk map. By using the AHP method, we calculated the weights resulting from the pairwise comparison matrices for the three resulting maps and the corresponding classes. The pairwise comparison matrices were filled by the same experts who were mentioned in Section 3.3. All resulting maps were prepared as GIS layers and then overlaid with the respective AHP weights, which were almost $54 \%$ for the forest fire susceptibility, $30 \%$ for the social vulnerability, and $16 \%$ for the infrastructural vulnerability layer (see Table 5). The final forest fire risk map was classified by natural breaks ('Jenks') and is represented in Figure 9 via four classes. This classification method yields classes that are based on natural groupings of the pixel values. Class breaks are specified in a way that the resulting groups are most similar and the differences between classes are maximized. Area and percentage of the forest fire risk map classes are represented in Table 6. The forest fire risk map reflects both the forest fire susceptibility (including the likelihood of ignition and the probability of spreading) and social/infrastructural vulnerability. The forest fire risk map shows that the slope aspect factor played a key role in the susceptibility of spreading, consequently raises the forest fire risk. For the other aspects, the susceptibility of a forest fire occurring is high due to the impact of other conditioning factors. Therefore, the applied ANN method could be trained well with all factors based on the inventory forest fire data and succeeded in predicting high forest fire susceptible areas. High temperature and low rainfall in the northern regions of the study area obviously increased the susceptibility of the forest fire ignition and spread. Although steep areas are generally more susceptible for forest fires, the human activity close to the main road (even with more moderate slopes in the northern parts) had a primary effect on the susceptibility and the risk map. The interaction of settlement areas (high social vulnerability) and infrastructural vulnerable areas with the high and moderate forest fire susceptibility resulted in high risk regions in the forest fire risk map (see Figure 9).

Table 6. Area and percentage of forest fire risk classes compared to the whole study area.

\begin{tabular}{cccc}
\hline Resulted Map & Classes & Area (ha) & Area (\%) \\
\hline Forest fire susceptibility & Very low & $24,930.87$ & 38.62 \\
& Low & $23,919.53$ & 37.06 \\
& Moderate & $14,958.09$ & 23.17 \\
& High & 729.61 & 1.14 \\
\hline
\end{tabular}




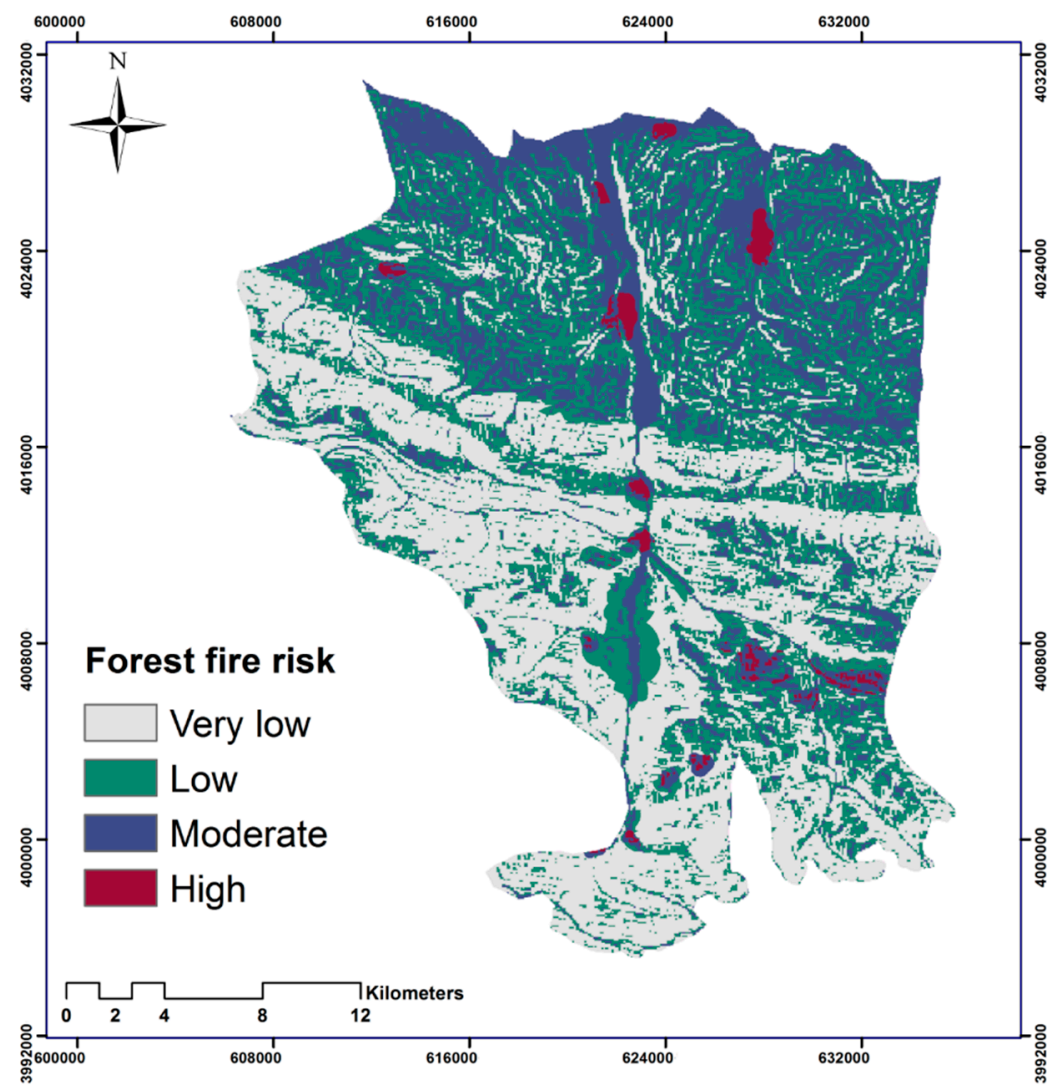

Figure 9. Forest fire risk map.

\section{Discussion and Conclusion}

Mapping the forest fire risk posed to human life and properties is an essential component of emergency land management, forest fire prevention, mitigation of adverse impacts, and response and recovery management [83]. As already discussed in the introduction section, forest fire susceptibility maps have often been used to priorities investments in forest fire prevention, and also for preparation planning. However, even considering social vulnerabilities leads to more effective forest fire risk management [84]. Since such risk maps can illustrate the location of the elements-at-risk, besides communities who have a lower capacity to deal with the fire and the spatial correlations between communities and fires, they are also more useful for land managers and firefighters for emergency planning in combating fires in real time. Therefore, a comprehensive forest fire mitigation and disaster management plan should concentrate on areas where there is an overlap between populations and their more vulnerable properties and a higher forest fire risk. In this regard, the forest fire susceptibility map of our study was generated using environmental variables. We considered the most available factors and prepared them as input data for the model. Training and testing data were generated using field survey GPS polygons and MODIS hotspot data. The field survey was done by the SWOAC [52]. According to the literature, a wide range of approaches have been used to predict areas with potential susceptibility to forest fires. Thus, different methods have been applied by various researchers to explore the potential role of relative factors that point to fire events. In this research, we generated a model using an ANN method with an MLP architecture that was trained with the BPA through ten-fold CV. The main limitation that we faced in this study was the dataset used. The fire inventory was from MODIS with a resolution of $1000 \mathrm{~m}$ while the resolution of the condition factors was $30 \mathrm{~m}$. The dataset from the SWOAC includes the polygons with detailed borders. However, this documentation does not include small forest fires. Therefore, for the cases of the extensive wildfires, we considered the GPS polygons rather than those of from MODIS. Still, for the small events, the MODIS dataset was applied. Thus, the dataset of the MODIS is more accurate 
in terms of the number of the forest fires. The GPS dataset is more reliable regarding the shape of the polygons of burned areas because of the low resolution of MODIS. Consequently, the integration of both sources resulted in a more reliable inventory dataset of the location and the extension area of the wildfires. Nevertheless, the resolution of the resulting inventory dataset was not the same as that of the input data. Therefore, this difference in the resolution resulted in some uncertainties, which are difficult to quantify.

The model was developed and trained based on the previous forest fire events between 2012 and 2017, and the relevant factors contributing to the forest fire. The performance of the model was evaluated by the RMSE, and the resulting forest fire susceptibility map was validated using the ROC curve. Both of these measures showed acceptable accuracies of the results of the model. The resulting forest fire susceptibility map with the highest accuracy revealed that the southern part of our study area is more susceptible to forest fires in the future. This matter illustrates that the factors of annual rainfall and annual mean temperature play an important role by creating extreme dryness, which is a crucial factor determining forest fires [85]. The areas with high forest fire susceptibility also have a close spatial correlation with the previously recorded forest fire events.

Although environmental variables contributing to the forest fire played an essential role in the assessment of susceptible forest fire areas, they are not the only reason for both forest fire susceptibility and risk. As some of the forest fires in in our case study are reported to be a result of human activity and the local people in particular SWOAC [52], considering the areas and some specific sites of human activity such as recreational areas can help to have a better understanding of the results of the forest fire susceptibility and risk. The distance from population concentration is considered to be relevant to human activity. Therefore, the closer regions to the settlements and population concentration can indicate a higher presence of human activity and consequently more susceptibility and risk of forest fire [31]. Thus, the population density and social vulnerability indicators were used, which were gained from different sources and, mostly, from census data. We also consider the areas with infrastructural valued assets and resources that are recognized as public/private properties. All indicators were weighted and ranked using expert knowledge and pairwise comparison matrices. Mostly, local experts were asked to contribute to this study, and they are mentioned in the acknowledgements section. The reason for selecting local experts to weight the indicators is that they are more familiar with the existing situation in our study area. These experts have different field backgrounds, like geography, geomorphology, meteorology, and wildlife. The selection of social vulnerability indicators may have some limitations, and the authors cannot be sure to have considered all relevant indicators that determine social vulnerability. However, we tried to localise the information that defines vulnerability in our case study. The social vulnerability generally depends on different characteristics, e.g., the country that the study area is located in, government support, and social features. Thus, the indicators may vary among different nations. The average life expectancy of houses, for instance, is a range between 10 and 15 years in our case study area. As this measure depends on the materials and different standards that are used for buildings, it may vary in other countries and even states. However, the concept of social vulnerability is a stable concept, and a large segment of the indicators are the same in different communities (e.g., age, gender and occupation). As we used the most relevant factors regarding forest fires and a large number of social/infrastructural vulnerability indicators, the performed methodology can easily be generalized and adapted to different locations like Australia, California, and Spain - i.e., fire-prone areas. Thus, the transferability of the method only requires minor changes and localization regarding social vulnerability indicators.

The novelty of our study is using both data-based ML and knowledge-based multi-criteria decision analyses for producing the forest fire risk map. Although there are several instances of using these methodologies separately for risk map generation, we provide an integration of using both methods for this aim. The reasons for using different methods for forest fire susceptibility mapping and the production of social/infrastructural vulnerability maps were described in Section 4.3. Our results emphasize the importance of considering a social/infrastructural vulnerability assessment when 
creating forest fire risk maps. Both resulting susceptibility and vulnerability maps were overlayed and analysed to understand how they correspond.

We propose that our future research can consider biodiversity and its contributing role in forest fires. For the detection of different tree species, convolutional neural networks can be applied. This method is a deep learning method, but it consists of a more significant number of various layers and requires a massive amount of training data. We also want to use other ML methods such as support vector machines and random forest for forest fire susceptibility modelling and mapping purposes.

Author Contributions: Conceptualization, O.G. and T.B.; methodology, O.G., and K.G.; software, O.G., and K.G.; validation, O.G. and K.G.; data curation, K.G.; writing-original draft preparation, O.G.; writing-review and editing, T.B., and J.A.; visualization, O.G. and K.G.; supervision, T.B. and J.A.; funding acquisition, T.B. All authors read and approved the final manuscript.

Funding: This research is partly funded by the Open Access Funding of Austrian Science Fund (FWF) through the GIScience Doctoral College (DK W 1237-N23).

Acknowledgments: We would like to thank four anonymous reviewers for their valuable comments. Special thanks are owed to Mihaela Alina Ristea and Sepideh Tavakkoli Piralilou, Department of Geoinformatics, Doctoral College University of Salzburg, Austria, Ghasem Lorestani, department of geomorphology and Rahim Bordi Anamoradnejad, Department of Geography, University of Mazandaran, Iran, Yousefzadeh, from SMOAC, Sirus Abbaszadeh and Kazem Parsapoor from SWOAC, and Jochen Albrecht, Hunter College, New York, USA. Open Access Funding by the Austrian Science Fund (FWF).

Conflicts of Interest: The authors declare no conflict of interest.

\section{References}

1. Liu, Q.; Shan, Y.; Shu, L.; Sun, P.; Du, S. Spatial and temporal distribution of forest fire frequency and forest area burnt in Jilin Province, Northeast China. J. For. Res. 2018, 29, 1233-1239. [CrossRef]

2. Preston, B.; Brooke, C.; Measham, T.G.; Smith, T.; Gorddard, R. Igniting change in local government: Lessons learned from a bushfire vulnerability assessment. Mitig. Adapt. Strateg. Glob. Chang. 2009, 14, 251-283. [CrossRef]

3. Ahn, Y.S.; Ryu, S.-R.; Lim, J.; Lee, C.H.; Shin, J.H.; Choi, W.I.; Lee, B.; Jeong, J.-H.; An, K.W.; Seo, J.I. Erratum to: Effects of forest fires on forest ecosystems in eastern coastal areas of Korea and an overview of restoration projects. Landsc. Ecol. Eng. 2014, 10, 239. [CrossRef]

4. Chowdhury, E.H.; Hassan, Q.K. Operational perspective of remote sensing-based forest fire danger forecasting systems. ISPRS J. Photogramm. Remote. Sens. 2015, 104, 224-236. [CrossRef]

5. Pourghasemi, H.R. GIS-based forest fire susceptibility mapping in Iran: A comparison between evidential belief function and binary logistic regression models. Scand. J. For. Res. 2016, 31, 80-98. [CrossRef]

6. Darvishsefat, A.; Mostafavi, M.; Etemad, V.; Jahdi, R. Wind Effect on Wildfire and Simulation of Its Spread (Case Study: Siahkal Forest in Northern Iran). J. Agr. Sci. Tech. 2014, 16, 1109-1121.

7. Miller, C.; Ager, A.A. A review of recent advances in risk analysis for wildfire management. Int. J. Wildland Fire 2013, 22, 1. [CrossRef]

8. Emrich, C.T.; Borden, K.A.; Schmidtlein, M.C.; Piegorsch, W.W.; Cutter, S.L. Vulnerability of U.S. Cities to Environmental Hazards. J. Homel. Secur. Emerg. Manag. 2007, 4, 4.

9. Van Westen, C. 3.10 Remote Sensing and GIS for Natural Hazards Assessment and Disaster Risk Management. Treatise Geomorphol. 2013, 3, 259-298.

10. Dwyer, A.; Zoppou, C.; Nielsen, O.; Day, S.; Roberts, S. Quantifying Social Vulnerability: A Methodology for Identifying Those at Risk to Natural Hazards; Australian Government: Canberra, Australia, 2004.

11. Aryal, J.; Louvet, R. Quantifying Bushfire Mapping Uncertainty Using Single and Multi-Scale Approach: A Case Study from Tasmania, Australia. In Proceedings of the GEOBIA 2016: Solutions and Synergies, Twente, The Netherlands, 14-16 September 2016.

12. Pourghasemi, H.R.; Rahmati, O. Prediction of the landslide susceptibility: Which algorithm, which precision? Catena 2018, 162, 177-192. [CrossRef]

13. Meena, S.R.; Ghorbanzadeh, O.; Blaschke, T. A Comparative Study of Statistics-Based Landslide Susceptibility Models: A Case Study of the Region Affected by the Gorkha Earthquake in Nepal. ISPRS Int. J. Geo-Inf. 2019, 8, 94. [CrossRef] 
14. Meena, S.R.; Mishra, B.K.; Piralilou, S.T. A Hybrid Spatial Multi-Criteria Evaluation Method for Mapping Landslide Susceptible Areas in Kullu Valley, Himalayas. Geosciences 2019, 9, 156. [CrossRef]

15. Shahabi, H.; Hashim, M. Landslide susceptibility mapping using GIS-based statistical models and Remote sensing data in tropical environment. Sci. Rep. 2015, 5, 9899. [CrossRef] [PubMed]

16. Eidsvig, U.M.K.; McLean, A.; Vangelsten, B.V.; Kalsnes, B.; Ciurean, R.L.; Argyroudis, S.; Winter, M.G.; Mavrouli, O.C.; Fotopoulou, S.; Pitilakis, K.; et al. Assessment of socioeconomic vulnerability to landslides using an indicator-based approach: Methodology and case studies. Bull. Int. Assoc. Eng. Geol. 2014, 73, 307-324. [CrossRef]

17. McCaffrey, S.; Toman, E.; Stidham, M.; Shindler, B. And Social science research related to wildfire management: An overview of recent findings and future research needs. Int. J. Wildland Fire 2013, 22, 15. [CrossRef]

18. Wigtil, G.; Hammer, R.B.; Kline, J.D.; Mockrin, M.H.; Stewart, S.I.; Roper, D.; Radeloff, V.C. Places where wildfire potential and social vulnerability coincide in the coterminous United States. Int. J. Wildland Fire 2016, 25, 896-908. [CrossRef]

19. Lueck, D.; Yoder, J. Clearing the Smoke from Wildfire Policy: An Economic Perspective; PERC: Bozeman, MT, USA, 2016.

20. Chuvieco, E.; Martínez, S.; Román, M.V.; Hantson, S.; Pettinari, M.L. Integration of ecological and socio-economic factors to assess global vulnerability to wildfire. Glob. Ecol. Biogeogr. 2014, 23, 245-258. [CrossRef]

21. Molina, J.R.; Silva, F.R.Y.; Herrera, M.Á. Integrating economic landscape valuation into Mediterranean territorial planning. Environ. Sci. Policy 2016, 56, 120-128. [CrossRef]

22. Poudyal, N.C.; Johnson-Gaither, C.; Goodrick, S.; Bowker, J.M.; Gan, J. Locating Spatial Variation in the Association Between Wildland Fire Risk and Social Vulnerability Across Six Southern States. Environ. Manag. 2012, 49, 623-635. [CrossRef]

23. Kamran, K.V.; Omrani, K.; Khosroshahi, S.S. Forest fire risk assessment using multi-criteria analysis: A case study kaleybar forest. In Proceedings of the International Conference on Agriculture, Environment and Biological Sciences, Antalya, Turkey, 4-5 June 2014; pp. 30-33.

24. Pourghasemi, H.R.; Beheshtirad, M.; Pradhan, B. A comparative assessment of prediction capabilities of modified analytical hierarchy process (m-AHP) and Mamdani fuzzy logic models using NETCAD-GIS for forest fire susceptibility mapping. Geomat. Nat. Hazards Risk 2016, 7, 861-885. [CrossRef]

25. Suryabhagavan, K.; Alemu, M.; Balakrishnan, M. Gis-based multi-criteria decision analysis for forest fire susceptibility mapping: A case study in harenna forest, Southwestern Ethiopia. Trop. Ecol. 2016, 57, $33-43$.

26. Liu, X.-P.; Zhang, J.-Q.; Tong, Z.-J.; Bao, Y. GIS-based multi-dimensional risk assessment of the grassland fire in northern China. Nat. Hazards 2012, 64, 381-395. [CrossRef]

27. Ghorbanzadeh, O.; Blaschke, T. Wildfire susceptibility evaluation by integrating an analytical network process approach into GIS-based analyses. Int. J. Adv. Sci. Eng. Technol. 2018, 6, 48-53.

28. De Souza, F.T.; Koerner, T.C.; Chlad, R. A data-based model for predicting wildfires in Chapada das Mesas National Park in the State of Maranhão. Environ. Earth Sci. 2015, 74, 3603-3611. [CrossRef]

29. Dutta, R.; Das, A.; Aryal, J. Big data integration shows Australian bush-fire frequency is increasing significantly. R. Soc. Open Sci. 2016, 3, 150241. [CrossRef]

30. Dutta, R.; Aryal, J.; Das, A.; Kirkpatrick, J.B. Deep cognitive imaging systems enable estimation of continental-scale fire incidence from climate data. Sci. Rep. 2013, 3, 3188. [CrossRef]

31. Kim, S.J.; Lim, C.-H.; Kim, G.S.; Lee, J.; Geiger, T.; Rahmati, O.; Son, Y.; Lee, W.-K. Multi-Temporal Analysis of Forest Fire Probability Using Socio-Economic and Environmental Variables. Remote. Sens. 2019, 11, 86. [CrossRef]

32. Ghorbanzadeh, O.; Blaschke, T.; Aryal, J.; Gholaminia, K. A new GIS-based technique using an adaptive neuro-fuzzy inference system for land subsidence susceptibility mapping. J. Spat. Sci. 2018, 1-17. [CrossRef]

33. Korup, O.; Stolle, A. Landslide prediction from machine learning. Geol. Today 2014, 30, 26-33. [CrossRef]

34. Carr, J.A. Pre-Disaster Integration of Community Emergency Response Teams within Local Emergency Management Systems. M.Sc. Thesis, Dep of Emergency Management, North Dakota State University, Fargo, ND, USA, 2014.

35. King, D.; MacGregor, C. Using social indicators to measure community vulnerability to natural hazards. Aust. J. Emerg. Manag. 2000, 15, 52. 
36. Eidsvig, U.; McLean, A.; Vangelsten, B.; Kalsnes, B.; Ciurean, R.; Argyroudis, S.; Winter, M.; Corominas, J.; Mavrouli, O.; Fotopoulou, S. In Socio-economic vulnerability to natural hazards-proposal for an indicator-based model. In Proceedings of the 3rd International Symposium on Geotechnical Safety and Risk (ISGSR2011), Munich, Germany, 2-3 June 2011; pp. 2-3.

37. Contreras, D.; Blaschke, T.; Tiede, D.; Jilge, M. Monitoring recovery after earthquakes through the integration of remote sensing, gis, and ground observations: The case of L'Aquila (Italy). Cartogr. Geogr. Inf. Sci. 2016, 43, 115-133. [CrossRef]

38. Cutter, S.L.; Boruff, B.J.; Shirley, W.L. Social Vulnerability to Environmental Hazards*. Soc. Sci. Q. 2003, 84, 242-261. [CrossRef]

39. Norris, F.H. Disasters in urban context. J. Urban Health 2002, 79, 308-314. [CrossRef] [PubMed]

40. Malczewski, J. Ordered weighted averaging with fuzzy quantifiers: GIS-based multicriteria evaluation for land-use suitability analysis. Int. J. Appl. Earth Obs. Geoinf. 2006, 8, 270-277. [CrossRef]

41. Cabrera-Barona, P.; Ghorbanzadeh, O. Comparing Classic and Interval Analytical Hierarchy Process Methodologies for Measuring Area-Level Deprivation to Analyze Health Inequalities. Int. J. Environ. Res. Public Heal. 2018, 15, 140. [CrossRef] [PubMed]

42. Feizizadeh, B.; Ghorbanzadeh, O. GIS-based Interval Pairwise Comparison Matrices as a Novel Approach for Optimizing an Analytical Hierarchy Process and Multiple Criteria Weighting. Gi_Forum 2017, 1, 27-35. [CrossRef]

43. Shahabi, H.; Khezri, S.; Bin Ahmad, B.; Hashim, M. Landslide susceptibility mapping at central Zab basin, Iran: A comparison between analytical hierarchy process, frequency ratio and logistic regression models. Catena 2014, 115, 55-70. [CrossRef]

44. Franěk, J.; Kresta, A. Judgment Scales and Consistency Measure in AHP. Procedia Econ. Financ. 2014, 12, 164-173. [CrossRef]

45. Alexakis, D.; Sarris, A. Environmental and human risk assessment of the prehistoric and historic archaeological sites of western Crete (Greece) with the use of GIs, remote sensing, fuzzy logic and neural networks. In Proceedings of the Euro-Mediterranean Conference, Limassol, Cyprus, 29 October-3 November 2010; Springer: Berlin/Heidelberg, Germany, 2010; pp. 332-342.

46. Gaither, C.J.; Poudyal, N.C.; Goodrick, S.; Bowker, J.; Malone, S.; Gan, J. Wildland fire risk and social vulnerability in the Southeastern United States: An exploratory spatial data analysis approach. For. Policy Econ. 2011, 13, 24-36. [CrossRef]

47. Kolden, C.A.; Abatzoglou, J.T. Spatial Distribution of Wildfires Ignited under Katabatic versus Non-Katabatic Winds in Mediterranean Southern California USA. Fire 2018, 1, 19. [CrossRef]

48. Lautenberger, C. Mapping areas at elevated risk of large-scale structure loss using Monte Carlo simulation and wildland fire modeling. Fire Saf. J. 2017, 91, 768-775. [CrossRef]

49. Sayad, Y.O.; Mousannif, H.; Al Moatassime, H. Predictive modeling of wildfires: A new dataset and machine learning approach. Fire Saf. J. 2019, 104, 130-146. [CrossRef]

50. Ganteaume, A.; Camia, A.; Jappiot, M.; San-Miguel-Ayanz, J.; Long-Fournel, M.; Lampin, C. A review of the main driving factors of forest fire ignition over Europe. Environ. Manag. 2013, 51, 651-662. [CrossRef] [PubMed]

51. Pourtaghi, Z.S.; Pourghasemi, H.R.; Rossi, M. Forest fire susceptibility mapping in the minudasht forests, golestan province. Iran. Environ. Earth Sci. 2015, 73, 1515-1533. [CrossRef]

52. SWOAC. A National Project of Mazandaran Province; SWOAC: Mazandaran, Iran, 2018.

53. SMOAC. A National Project of Mazandaran Province; SMOAC: Mazandaran, Iran, 2018.

54. Hirano, A.; Welch, R.; Lang, H. Mapping from ASTER stereo image data: DEM validation and accuracy assessment. ISPRS J. Photogramm. Remote. Sens. 2003, 57, 356-370. [CrossRef]

55. Castruccio, S.; Nadzir, M.S.M.; Dominick, D.; Thota, A.; Crippa, P.; Mead, M.I.; Latif, M.T.; Nadzir, M.S.M. Impact of the 2015 wildfires on Malaysian air quality and exposure: A comparative study of observed and modeled data. Environ. Res. Lett. 2018, 13, 044023.

56. Cusworth, D.H.; Mickley, L.J.; Sulprizio, M.P.; Liu, T.; E Marlier, M.; DeFries, R.S.; Guttikunda, S.K.; Gupta, P. Quantifying the influence of agricultural fires in northwest India on urban air pollution in Delhi, India. Environ. Res. Lett. 2018, 13, 044018. [CrossRef] 
57. Cattau, M.E.; Marlier, M.E.; DeFries, R. Effectiveness of Roundtable on Sustainable Palm Oil (RSPO) for reducing fires on oil palm concessions in Indonesia from 2012 to 2015. Environ. Res. Lett. 2016, 11, 105007. [CrossRef]

58. Gilks, W. Markov Chain Monte Carlo in Practice; Chapman and Hall/CRC: London, UK, 1995.

59. Witten, I.H.; Frank, E.; Hall, M.A.; Pal, C.J. Data Mining: Practical Machine Learning Tools and Techniques; Morgan Kaufmann: Burlington, MA, USA, 2016.

60. Boria, R.A.; Olson, L.E.; Goodman, S.M.; Anderson, R.P. Spatial filtering to reduce sampling bias can improve the performance of ecological niche models. Ecol. Model. 2014, 275, 73-77. [CrossRef]

61. Wiens, T.S.; Dale, B.C.; Boyce, M.S.; Kershaw, G.P. Three way k-fold cross-validation of resource selection functions. Ecol. Model. 2008, 212, 244-255. [CrossRef]

62. Goldarag, Y.J.; Mohammadzadeh, A.; Ardakani, A.S. Fire Risk Assessment Using Neural Network and Logistic Regression. J. Indian Soc. Remote Sens. 2016, 44, 885-894. [CrossRef]

63. Gorsevski, P.V.; Brown, M.K.; Panter, K.; Onasch, C.M.; Simic, A.; Snyder, J. Landslide detection and susceptibility mapping using lidar and an artificial neural network approach: A case study in the cuyahoga valley national park, Ohio. Landslides 2016, 13, 467-484. [CrossRef]

64. Paola, J.D.; Schowengerdt, R.A. A review and analysis of backpropagation neural networks for classification of remotely-sensed multi-spectral imagery. Int. J. Remote. Sens. 1995, 16, 3033-3058. [CrossRef]

65. Neaupane, K.; Achet, S. Use of backpropagation neural network for landslide monitoring: A case study in the higher Himalaya. Eng. Geol. 2004, 74, 213-226. [CrossRef]

66. Bi, R.; Schleier, M.; Rohn, J.; Ehret, D.; Xiang, W. Landslide susceptibility analysis based on ArcGIS and Artificial Neural Network for a large catchment in Three Gorges region, China. Environ. Earth Sci. 2014, 72, 1925-1938. [CrossRef]

67. Pascale, S.; Parisi, S.; Mancini, A.; Schiattarella, M.; Conforti, M.; Sole, A.; Murgante, B.; Sdao, F. Landslide susceptibility mapping using artificial neural network in the urban area of senise and san costantino Albanese (Basilicata, Southern Italy). In Proceedings of the International Conference on Computational Science and Its Applications, Ho Chi Minh City, Vietnam, 24-27 June 2013; Springer: Berlin/Heidelberg, Germany, 2013; pp. 473-488.

68. De Brito, M.M.; Evers, M.; Almoradie, A.D.S. Participatory flood vulnerability assessment: A multi-criteria approach. Hydrol. Earth Syst. Sci. 2018, 22, 373-390. [CrossRef]

69. Malczewski, J. GIS-based land-use suitability analysis: A critical overview. Prog. Plan. 2004, 62, 3-65. [CrossRef]

70. Entani, T.; Sugihara, K. Uncertainty index based interval assignment by Interval AHP. Eur. J. Oper. Res. 2012, 219, 379-385. [CrossRef]

71. Duleba, S.; Moslem, S. Examining Pareto optimality in analytic hierarchy process on real Data: An application in public transport service development. Expert Syst. Appl. 2019, 116, 21-30. [CrossRef]

72. Vidal, L.-A.; Marle, F.; Bocquet, J.-C. Using a Delphi process and the Analytic Hierarchy Process (AHP) to evaluate the complexity of projects. Expert Syst. Appl. 2011, 38, 5388-5405. [CrossRef]

73. Saaty, T.L.; Vargas, L.G. Prediction, Projection, and Forecasting: Applications of the Analytic Hierarchy Process in Economics, Finance, Politics, Games, and Sports; Kluwer Academic Pub: Boston, MA, USA, 1991.

74. Saaty, T.L. Some Mathematical Concepts of the Analytic Hierarchy Process. Behaviormetrika 1991, 18, 1-9. [CrossRef]

75. Malczewski, J.; Rinner, C. Multicriteria Decision Analysis in Geographic Information Science; Springer: New York, NY, USA, 2016.

76. Ghorbanzadeh, O.; Feizizadeh, B.; Blaschke, T. Multi-criteria risk evaluation by integrating an analytical network process approach into gis-based sensitivity and uncertainty analyses. Geomat. Nat. Hazards Risk 2018, 9, 127-151. [CrossRef]

77. Ghorbanzadeh, O.; Rostamzadeh, H.; Blaschke, T.; Gholaminia, K.; Aryal, J. A new GIS-based data mining technique using an adaptive neuro-fuzzy inference system (ANFIS) and k-fold cross-validation approach for land subsidence susceptibility mapping. Nat. Hazards 2018, 1, 497-517. [CrossRef]

78. Bui, D.T.; Pradhan, B.; Löfman, O.; Revhaug, I.; Dick, O.B. Landslide susceptibility mapping at Hoa Binh province (Vietnam) using an adaptive neuro-fuzzy inference system and GIS. Comput. Geosci. 2012, 45, 199-211. 
79. Pham, B.T.; Pradhan, B.; Bui, D.T.; Prakash, I.; Dholakia, M. A comparative study of different machine learning methods for landslide susceptibility assessment: A case study of Uttarakhand area (India). Environ. Model. Softw. 2016, 84, 240-250. [CrossRef]

80. Popoola, O.M.; Munda, J.; Mpanda, A. Residential lighting load profile modelling: Anfis approach using weighted and non-weighted data. Energy Effici. 2018, 11, 169-188. [CrossRef]

81. Abrams, J.; Nielsen-Pincus, M.; Paveglio, T.; Moseley, C. Community wildfire protection planning in the american west: Homogeneity within diversity? J. Environ. Plan. Manag. 2016, 59, 557-572. [CrossRef]

82. Feizizadeh, B.; Blaschke, T. Landslide risk assessment based on gis multi-criteria evaluation: A case study in bostan-abad county, Iran. J. Earth Sci. Eng. 2011, 1, 66-77.

83. Haas, J.R.; Calkin, D.E.; Thompson, M.P. A national approach for integrating wildfire simulation modeling into Wildland Urban Interface risk assessments within the United States. Landsc. Urban. Plan. 2013, 119, 44-53. [CrossRef]

84. Solangaarachchi, D.; Griffin, A.L.; Doherty, M.D. Social vulnerability in the context of bushfire risk at the urban-bush interface in Sydney: A case study of the Blue Mountains and Ku-ring-gai local council areas. Nat. Hazards 2012, 64, 1873-1898. [CrossRef]

85. Bedia, J.; Herrera, S.; Camia, A.; Moreno, J.M.; Gutiérrez, J.M. Forest fire danger projections in the mediterranean using ensembles regional climate change scenarios. Clim. Chang. 2014, 122, 185-199. [CrossRef]

(C) 2019 by the authors. Licensee MDPI, Basel, Switzerland. This article is an open access article distributed under the terms and conditions of the Creative Commons Attribution (CC BY) license (http://creativecommons.org/licenses/by/4.0/). 